\title{
The Aggregate Implications of Mergers and Acquisitions
}

\author{
Joel M. David* \\ University of California, Los Angeles \\ JOB MARKET PAPER
}

November 7, 2011

\begin{abstract}
Mergers and acquisitions can play a transformative role in the evolution of firms and industries and have become an important feature of the US economy, representing about $5 \%$ of GDP and $80 \%$ of total capital reallocation among large US firms. In this paper, I develop a search-theoretic model of mergers and acquisitions in a dynamic general equilibrium setting and assess the implications for aggregate economic performance. I use a transaction-level dataset to document a number of empirical patterns in US merger activity: (1) acquiring firms are generally larger and more profitable than their targets; (2) there is a large degree of positive assortative matching between transacting firms; and (3) acquirers tend to be the largest and most profitable firms, but targets are not the smallest or least profitable. I build a parsimonious model that is able to address these facts and nests several existing theories of merger activity as special cases. I explore the merger patterns predicted by these theories and show that each meets difficulties in fitting the full set of empirical facts. I calibrate the model to match moments from the transaction-level data, as well as other salient features of the US economy. The calibrated model is capable of replicating the stylized facts quite closely and sheds new light as to how surplus is generated from merger and how the gains are split. I find that merger activity generates potentially large long-run gains in aggregate performance, measuring about $30 \%$ in aggregate productivity and output, and about $11 \%$ in welfare.
\end{abstract}

*I am extremely grateful to Hugo Hopenhayn for his invaluable guidance, as well as Andy Atkeson, Pierre-Olivier Weill, and Andrea Eisfeldt for many insightful comments and suggestions. I also thank seminar participants at the UCLA Macroeconomics Proseminar, IO Workshop, and the UCLA Anderson Brown Bag Seminar in Finance for helpful comments. Email: jdavid7@ucla.edu. 


\section{Introduction}

In 1987, Microsoft purchased Forethought Inc. for \$14 million, its first significant acquisition. The software developed by Forethought is now Microsoft PowerPoint. Yahoo!'s first large acquisition was of Four11 Corporation in 1997 for $\$ 92$ million. Four11's RocketMail product forms the basis of Yahoo! Mail, which boasted 281 million subscribers by 2010. In 2004, Google acquired Where 2 Technologies, a Sydney-based startup company where two Danish brothers were developing a mapping software. This application is now Google Maps, the number 1 mapping site in the world. ${ }^{1}$

Mergers and acquisitions (M\&A) play an important and even transformative role in the evolution of many firms and industries. For example, Microsoft has made 138 acquisitions since 1987, Google has made 93 since 2000, and Yahoo! has made 70 since 1997. ${ }^{2}$ Indeed, as illustrated by the examples above, many of the products that we most closely associate with individual brands were in fact developed by others. Moreover, it is not necessarily the largest transactions that have the most significant impact on later performance. Rather, the constant transfer of new or lesser developed ideas and products may be an important factor in shaping the ex-post evolution of the transacting firms and the industries in which they operate.

M\&A plays an equally prominent role in the aggregate economy and has become an important feature of the US business environment. From 1980 to 2009, M\&A has averaged a massive $5 \%$ of GDP annually, a figure that has been trending upward with a peak of almost $16 \%$ in $1998 .^{3}$ Because the capital-output ratio in the private business sector is approximately 1 , the rate of capital reallocation occurring through M\&A is similar, averaging about $4.5 \%$ annually and reaching a high of nearly $15 \%$ in $1998 .{ }^{4}$ Finally, M\&A composes the lion's share of total capital reallocation taking place among large US firms. From 1971 to 2007, M\&A has averaged about 65\% of total capital reallocation annually among these firms, with its share growing to over $80 \%$ in 2007.5 By these measures, M\&A represents an important, and indeed dominant, vehicle for capital reallocation in the US economy.

Would Google and Microsoft have achieved their current status if they had not acquired the

\footnotetext{
${ }^{1}$ For PowerPoint, see The New York Times, 1987, “Company News: Microsoft Buys Software Unit,” July 31. Ironically, PowerPoint was first developed for the Apple Macintosh computer. For Yahoo! Mail, see Cnet News, 1997, "Yahoo Buys Four11 for Free Email," October 8 and The Wall Street Journal, 2010, "Yahoo Revamps Mail Service," September 11. For Google Maps, see Cnet News, 2005, "Google Mapper: Take Browsers to the Limit," July 28, The Sydney Morning Herald, 2009, “Look Out Outlook, Google's Wave is Coming," May 29, and https:/ / sites.google.com/a/pressatgoogle.com/zamaps/fun-facts-about-maps.

${ }^{2}$ Data from Alacra, Inc., downloaded from http:/ / www.alacrastore.com/.

${ }^{3}$ Data are from SDC Platinum and the Bureau of Economic Analysis and are described in more detail below. To the extent that SDC does not include all M\&A activity, its share of GDP is likely to be understated.

${ }^{4}$ The reallocation rate is calculated as the value of M\&A divided by the total value of the US capital stock. The capital stock is measured as the stock of private, nonresidential fixed assets. Data are from the same sources as above and the same disclaimer about possible understatement applies. M\&A has averaged about $42 \%$ of de novo business investment over this same period.

${ }^{5}$ Following Eisfeldt and Rampini (2006), total reallocation is defined as the sum of expenditures on acquisitions and sales of property, plant and equipment. Data are for Compustat firms and are downloaded from Andrea Eisfeldt's website at http://www.kellogg.northwestern.edu/faculty/eisfeldt/.
} 
products that they have, such as Google Maps and PowerPoint? In reverse, would these products have achieved their prominence had they not been transferred to Google and Microsoft via M\&A? Indeed, would their developers have even entered the market if they had not had the prospect of being acquired and incorporated into the product portfolio of their larger competitors? Finally, how does this reallocation of ideas and resources across firms influence aggregate performance and shape the economic landscape in which firms operate? Despite the ubiquity of M\&A both for individual firms and for the economy as a whole, the economic role and significance of M\&A activity is still not well understood.

In this paper, I assess the implications of M\&A for aggregate economic performance. To do so, I build a theory of the M\&A market, the incentives driving individual M\&A decisions, and the mechanisms through which firm outcomes from M\&A aggregate to affect macroeconomic performance. M\&A serves as a vehicle for resource reallocation, transferring products and ideas among firms. Through this process, M\&A influences economic aggregates by reshaping the distribution of resources across firms and changing the dynamic incentives for entry and exit. Some firms grow through acquisition, others capitalize on their ideas by selling them and exiting the industry, and the prospect of participating in the M\&A market affects the entry decisions of entrepreneurs with new product ideas.

The model I develop is one of a dynamic industry in the spirit of Hopenhayn (1992) and Melitz (2003). Heterogeneous firms are monopolistically competitive on the output market and make standard pricing, entry, and exit decisions. Additionally, firms have the opportunity to participate in a merger market, in which the products being exchanged are the firms themselves. Mergers provide firms an avenue to potentially enhance their characteristics by incorporating those of another firm. Upon merger, the characteristics of the continuing firm evolve as an aggregate over those of the two pre-merger entities, the path determined by a "merger technology" to which firms have access. This setup lends itself to a natural tradeoff. Firms would like to grow through acquisition or realize the immediate gains from sale, but not every firm is a profitable partner in the sense of generating positive surplus through merger.

The corporate finance literature has highlighted the importance of search, screening, and bargaining in the M\&A market. ${ }^{6}$ In this light, I propose a search-theoretic model of the merger market in the spirit of Shimer and Smith (2000) and Shimer and Smith (2001a). Firms must make costly investments in searching for candidate partners to purchase or to sell themselves to. Upon meeting, the parties bargain over any surplus that may be generated and decide whether to consummate or reject the transaction. Whether the transaction creates positive surplus depends quite intuitively on whether the value of the post-merger entity exceeds the sum of the two pre-merger firms. In a departure from standard search environments, the model allows for repeat acquisitions, a phenomenon that is common in the data. The presence of firm heterogeneity in conjunction with search and matching frictions gives rise to a rich set of potential matching patterns, a feature I exploit to explore the implications of existing theories of merger activity and to discipline the merger

\footnotetext{
${ }^{6}$ See, for example, DePamphilis (2009) and Rhodes-Kropf and Robinson (2008), discussed in more detail below.
} 
technology in the numerical analysis.

I obtain data on individual M\&A transactions in the US over the period 1977-2009 and establish a number of stylized facts regarding M\&A activity among US firms. Several striking empirical patterns emerge. Consistent with previous evidence, acquiring firms are generally larger and more profitable than their targets. ${ }^{7}$ However, while acquirers are generally larger and more profitable than the median firm, targets are not the smallest nor the least profitable. Indeed, the median target is almost identical to the median firm. Next, I show that there is a large positive correlation between the size and profitability of acquirers and their targets. Large and profitable firms tend to transact with other large and profitable firms and small firms with other small firms. The joint distribution of acquirer and target characteristics reveals a large degree of positive assortative matching in mergers. ${ }^{8}$

To properly measure the aggregate effects of M\&A, we must first understand the incentives driving individual M\&A decisions and so the technology generating gains upon transaction. Although the model does not in general yield analytic solutions, I am able to characterize the predicted matching patterns under several prevalent theories of merger activity that are nested by the merger technology. These include a theory of no gains from bundling, where mergers are motivated solely by scale efficiencies through fixed cost savings, the q-theory of mergers for the transfer of resources from low to high productivity firms as outlined by Jovanovic and Rousseau (2002), and lastly a theory of synergistic mergers through asset complementarities as in RhodesKropf and Robinson (2008). I show that each of these theories meets difficulties in fitting the full set of observed matching patterns and explore the economic intuition underlying these results.

In this light, I proceed by calibrating the model to match several of the empirical facts from the transaction-level data. I use the observed merger patterns to infer the parameters governing the merger technology, as well as the bargaining process and the costs of search. Intuitively, observing the characteristics of transacting firms reveals information as to how surplus is generated (or not) from various possible combinations of independent entities, enabling me to discipline the shape of the merger technology, in particular, the parameters determining the role of synergies and productivity enhancement. I use data on the rate of merger and the merger premium to pin down the costs of search and the split of surplus, respectively, exploiting an intuitive relationship between the merger premium and the bargaining powers of the transacting parties revealed by the model. I calibrate the remaining parameters of the model to match a number of salient features of the US economy, and in particular, the firm size distribution. The calibrated model is able to match the targeted moments quite closely and performs well in replicating many of the non-targeted empirical merger patterns. The parameter estimates themselves are of independent interest, as they shed new light as to how surplus is generated upon merger and how the gains are split between the parties.

Finally, I use the calibrated model to quantitatively assess the impact of M\&A activity on ag-

\footnotetext{
${ }^{7}$ See, for example, Andrade et al. (2001).

${ }^{8}$ Rhodes-Kropf and Robinson (2008) point out a similar sorting pattern when examining the market-to-book ratios of paired acquirers and targets.
} 
gregate economic performance. To do so, I compare the aggregate outcomes from the calibrated economy to one with no M\&A. The latter is essentially a closed-economy version of Melitz (2003), a world that has been thoroughly explored in the literature, making it a natural benchmark to understand and quantify the influence of $\mathrm{M} \& \mathrm{~A}$ on economic outcomes. At the aggregate level, there is a tradeoff between the beneficial effects of $M \& A$ through more efficient industrial performance and the increased resource costs imposed by M\&A activity. M\&A imposes direct costs on the economy by absorbing resources in search on the merger market, as well as indirect costs by changing the number of operating firms and the amount of new firm creation that the economy must sustain. After accounting for these margins, the model suggests that M\&A has a great potential for improving long-run economic performance. In particular, I find that in stationary equilibrium, M\&A activity generates gains of about $30 \%$ in both aggregate productivity and output, a similar decline in the aggregate price level, and a welfare increase of about $11 \%$.

This paper relates to several branches of literature. There are, of course, vast bodies of work in industrial organization and corporate finance on the causes and consequences of M\&A. Where these have tended to focus on the antitrust implications and financial market aspects of M\&A, respectively, I take a different perspective in analyzing the empirical patterns of M\&A and assessing its aggregate effects in a dynamic general equilibrium framework. ${ }^{9}$ As I cannot hope to do justice to the numerous contributions made in industrial organization and finance, I will focus on a few strands of literature that are particularly relevant.

First, there is a small body of existing work addressing M\&A activity from a macroeconomic perspective. Jovanovic and Rousseau (2002) propose the q-theory of mergers, one of pure reallocation in which mergers serve as a vehicle for resources to flow from low to high productivity firms. Because productivity is embodied in the firm, perhaps due to superior management or projects, the transferred resource inherits the productivity of its purchaser, giving room for surplus to be generated when firms of differing productivities transact. Jovanovic and Rousseau (2008) show how merger waves can arise as a response to the availability of a new general purpose technology, such as electricity or IT. In the spirit of the q-theory, mergers serve as a way for resources to be transferred to those firms most capable of deploying the new technology. Eisfeldt and Rampini (2006) rely on the q-theory in measuring the gains to reallocation and investigating the cyclical properties of reallocative activity. In the finance literature, Rhodes-Kropf and Robinson (2008) document positive sorting on the market-to-book ratios of acquirers and targets and develop a synergistic model of mergers driven by asset complementarities to match this fact. Among several

\footnotetext{
${ }^{9}$ For recent reviews of these lines of work, see, for example, Whinston (2007) and Andrade et al. (2001). In Table 1, I show that the median transaction value among US firms from 1977-2009 was \$31 million in real 2005 dollars, falling well below the current threshold of about $\$ 63$ million that requires the transaction to be reported to the FTC and DOJ under the Hart-Scott-Rodino Act. The majority of transactions are not the headline-grabbers involving two large corporations coming together, but rather, most are small enough to never come to the attention of the US regulatory agencies. Further, only a small number of transactions reviewed by the competition authorities warrant a review. For example, between 2001 and 2010, an annual average of only 3\% of reported transactions necessitated a second request, with only a subset of these resulting in a legal challenge (see the Hart-Scott-Rodino Annual Reports available at http://www.ftc.gov/bc/anncompreports.shtm). Together, these facts motivate my focus on the redistributional effects of M\&A from an aggregate perspective.
} 
notable differences between my paper and these, I allow for endogenous productivity evolution through M\&A at the firm level and consider the impact of M\&A activity on economic aggregates through reallocation, entry, and exit in a general equilibrium framework. In contrast, these papers have taken firm-level productivity as exogenous and invariant to M\&A activity, and have not considered its aggregate effects. Additionally, I allow for a more general merger technology which I discipline quantitatively by matching the empirical merger patterns. Both the q-theory and the theory of purely synergistic mergers are nested in my model and I address their implications in detail in the text of the paper.

Second, there is a recent and growing literature on the potential for aggregate performance gains through the reallocation of resources to more efficient firms. Recent examples include Hsieh and Klenow (2009) and Restuccia and Rogerson (2008). In considering the potentially beneficial effects of reallocation across heterogeneous firms, these papers share a common agenda with mine. This line of work has typically focused on the potential gains from reallocation stemming from the removal of a set of more abstract distortions preventing full allocative efficiency. ${ }^{10}$ In contrast, I model a particular vehicle for reallocation and the associated costs, the market that is formed for such activities, and incorporate the empirical facts on observed reallocation activity to discipline the gains accruing to the transacting firms. By doing so, I show another mechanism through which reallocation can spur performance improvements and the potentially detrimental impact of a different sort of policy, that is, one preventing M\&A activity.

Lastly, the search-theoretic setup of the merger market connects this paper to a recent literature on the properties and matching predictions of search environments with ex-ante heterogeneous agents. Particularly relevant papers include Shimer and Smith (2000) and Shimer and Smith (2001a), as well as an earlier predecessor, Lu and McAfee (1996). I extend the standard environment by allowing for repeat matching without need of dissolving one's previous match, and for heterogeneity in the value of rejecting a candidate partner, captured by the value of the firm as a standalone entity. Moreover, I endogenize the values of the agents in the model both in accepting and rejecting matches through their prospects on the output market. An additional contribution comes through the calibration and computation of the model's equilibrium, as I am unaware of any other work that has done so in this type of environment. Finally, this paper shows, I believe, that the M\&A market represents an interesting and important application of this general framework.

The remainder of the paper is organized as follows. In the next section, I present the empirical facts regarding observed merger activity. I include a discussion of the roles of search and repeat acquisitions, features of the market that will prove important in the theoretical framework. In Section 3, I outline the model and characterize the matching predictions of existing theories of merger activity, with particular focus on how they line up with the stylized facts. I describe the calibration and numerical results in Section 4, highlighting the parameter estimates, as they are of

\footnotetext{
${ }^{10}$ Somewhat relatedly, Eisfeldt and Rampini (2008) focus on a specific distortion and show how agency frictions can hinder resource reallocation across managers of differing quality, resulting in lower levels of aggregate productivity. Lagos (2006) shows a similar result stemming from frictions in the labor market.
} 
some independent interest, as well as the performance of the model in matching some salient nontargeted features of the M\&A market. In Section 5, I quantitatively explore the aggregate impact of M\&A activity. Section 6 concludes.

\section{The Patterns and Processes of Mergers and Acquisitions}

In this section, I present a number of stylized facts regarding the patterns of M\&A activity observed in the universe of US firms. Additionally, I describe the process underlying a typical M\&A transaction as outlined in the corporate finance literature and highlight the central roles of search, matching, and bargaining in the dealmaking process. Finally, I make note of the importance of repeat acquisitions, a phenomenon that stands in distinction to the markets typically analyzed in the search literature.

\subsection{Empirical Patterns in Mergers and Acquisitions}

I begin by documenting a number of stylized facts regarding the empirical patterns in observed M\&A activity. I obtain transaction-level data on US mergers and acquisitions from the Thomson Reuters SDC Platinum database. SDC Platinum includes all transactions involving at least 5\% of the ownership of a company where the transaction was valued at $\$ 1$ million or more (after 1992, all deals are covered) or where the value of the transaction was undisclosed. Public and private transactions are covered. I extract transactions announced between 1977 and 2009. I include domestic transactions with a deal value exceeding $\$ 1$ million. I limit the sample to completed transactions and those not classified as hostile takeovers. I exclude transactions in which the acquirer owns less than $50 \%$ of the target post-merger, or owned over $50 \%$ prior to merger. Finally, I remove firms with non-relevant ownership status (e.g., government-owned) and obvious data entry errors. The final sample consists of 57,858 transactions.

Deal characteristics contained in SDC include the transaction value (purchase price) and the merger premium, which is defined as the percentage by which the purchase price exceeds the current market value of the target, when available. Additionally, SDC contains a number of pretransaction statistics on the parties involved in each deal. In particular, I obtain sales, employment, property, plant, and equipment (PP\&E), earnings before interest, taxes, depreciation, and amortization (EBITDA), and market value for both the acquirer and target firm. PP\&E and EBITDA are used as proxies for the size of the firm's capital stock and profitability. Firm-level performance variables in SDC are generally calculated for the 12 month period preceding the deal announcement. I deflate all nominal variables to constant 2005 dollars using the CPI. The firm-level operating data in SDC is only available for a subset of transactions, in large part because many of the firms in the database are privately owned and are not required to report operating statistics to any regulatory agency. I describe the SDC data in more detail in the Appendix.

I obtain the same set of statistics for the universe of Compustat firms over the period ranging from 1977, which corresponds to the first announcement year in the SDC data, through 2009. 
This yields 210,275 firm-year observations. I match the SDC database to Compustat in order to associate the transacting firms with Compustat operating data. The match between SDC and Compustat is not straightforward, as the two datasets use different firm-level identifiers. I describe the matching process in detail in the Appendix. Of the approximately 58,000 transactions, 31,343 acquirers and 7,437 targets are successfully matched to Compustat. Not surprisingly, the set of successful matches corresponds quite closely to the set of firms classified as public in SDC. In contrasting the characteristics of transacting firms to the overall population of firms, it is important to ensure that the data is comparable. To this end, I use the Compustat operating statistics in any calculations that involve industry aggregates, e.g., industry means or medians. I use the SDC statistics in any calculations that do not, mainly because SDC provides more coverage of private companies, in particular targets. For example, sales are available for about 6,800 targets using Compustat and for 18,500 targets using SDC. I describe the Compustat data in more detail in the Appendix.

\subsubsection{Summary Statistics}

In Table 1, I report summary statistics of transaction values and merger premia. The merger premium is defined as the percent by which the purchase price exceeds the current market value of the target firm. The premium shown is calculated using the market value of the target firm 4 weeks prior to the merger announcement. This is to avoid the known runup in share prices once rumors of the merger begin to circulate. The mean transaction value is quite modest at $\$ 267$ million as is the median at only $\$ 31$ million. The difference reflects a great deal of right-skewness in the distribution of transaction values, that is, the majority of mergers are quite small with some very large outliers. The largest transaction by value is the merger between AOL and Time Warner in the year 2000, a deal valued at about $\$ 187$ billion in 2005 dollars.

After omitting about 500 transactions with negative premia (less than $8 \%$ of transactions where premia are available), there are about 6,000 transactions with reported premia. The mean premium is about $53 \%$ and the median $39 \%$. The level of the merger premium is substantial, implying that the majority of transactions are characterized by a purchase price substantially above the current market value of the target firm.

Table 1: Transaction Values and Premia

\begin{tabular}{lrr}
\hline & Trans. Val. (\$M) & Premium (\%) \\
\hline \hline Mean & 267.4 & 52.6 \\
Median & 31.0 & 39.0 \\
SD & $1,911.5$ & 65.8 \\
Max & $186,824.1$ & $1,937.0$ \\
Min & 0.9 & 0.0 \\
\hline $\mathrm{N}$ & 57,858 & 5,976 \\
\hline
\end{tabular}




\subsubsection{Buyers and Sellers}

In what seems a natural starting point to examine the patterns in M\&A activity, I begin by comparing the characteristics of acquirers and targets in individual matches. To do so, I calculate the mean and median log difference between acquirers and targets on several dimensions, including sales, employment, capital stock, profitability, and market value. I show the results in Table 2 . The first set of columns show statistics using the data as reported. The second set of columns show the same statistics after scaling by the industry medians for the acquirer and target, respectively. I make this adjustment to ensure that the results are not skewed by cross-industry differences between the transacting firms. Industries are defined at the 4-digit SIC level as reported in Compustat. Turning to the first set of columns, we see that acquirers are generally larger and more profitable than targets, on the scale of $2 \log$ points (a factor of about 7.4) consistently across all dimensions. Moreover, this is the case in about $90 \%$ of transactions. These patterns are qualitatively robust to scaling each firm by the median firm in its industry. In the large majority of transactions, acquirers are significantly larger and more profitable than the target they are purchasing. This fact is in line with the motivation behind the q-theory as outlined by Jovanovic and Rousseau (2002), i.e., the characteristics of acquirers and their targets suggest that the former exhibit higher productivity than the latter, perhaps due to better projects or superior management.

Table 2: Log Differences in Matched Acquirers and Targets

\begin{tabular}{lccccccc}
\hline & \multicolumn{3}{c}{ Reported } & & \multicolumn{3}{c}{ Scaled by Industry Medians } \\
\cline { 2 - 3 } & Mean & Median & $\%>0$ & & Mean & Median & $\%>0$ \\
\hline \hline Sales & 2.0 & 1.9 & 89.0 & & 1.6 & 1.4 & 81.7 \\
Employment & 2.0 & 1.8 & 87.1 & & 1.4 & 1.3 & 79.3 \\
PP\&E & 2.1 & 1.9 & 88.2 & & 1.6 & 1.5 & 79.9 \\
EBITDA & 2.1 & 1.9 & 90.0 & & 1.7 & 1.6 & 83.2 \\
Market Value & 2.3 & 2.1 & 95.3 & & 1.9 & 1.7 & 86.4 \\
\hline
\end{tabular}

Next, I ask how merger participants compare to the overall population of firms. Table 3 reports log differences between acquirers and targets and the median firm in their respective industries. Acquirers tend to be significantly larger than the median in their industry along every dimension. The mean and median differences are both substantial, hovering around 0.8 and 0.7 log points (a factor of about 2), respectively. Despite the large average differences, however, a considerable number of acquirers, generally slightly over one-third, actually fall below the industry median. Thus, it is not the case that acquirers are always the largest and most profitable firms. Turning to targets, interestingly (and perhaps surprisingly), the average target actually tends to be larger or approximately the same as the industry median. On 3 out of 5 dimensions, targets on average exceed the median firm in their industry. On the remaining two dimensions, the average target is only slightly smaller than the median firm. The differences are relatively small on all dimensions, especially as compared with the magnitudes by which acquirers differ from the median and by 
which acquirers exceed targets. Similarly, the median target generally lines up quite closely with the median firm, such that targets are just about equally represented on both sides of the median. Thus, we see that targets are actually not the smallest and least profitable firms, but rather, tend to be quite similar to the median firm in their industry.

Table 3: Log Deviations from Industry Median

\begin{tabular}{lcccccccc}
\hline & \multicolumn{3}{c}{ Acquirer } & & \multicolumn{3}{c}{ Target } \\
\cline { 2 - 5 } \cline { 7 - 9 } & Mean & Median & $\%>0$ & & Mean & Median & $\%>0$ \\
\hline \hline Sales & 0.75 & 0.58 & 64.6 & & 0.14 & 0.00 & 49.4 \\
Employment & 0.67 & 0.50 & 63.1 & & 0.10 & 0.00 & 48.8 \\
PP\&E & 0.79 & 0.61 & 63.8 & & 0.11 & 0.00 & 49.7 \\
EBITDA & 0.74 & 0.57 & 64.1 & & -0.07 & -0.01 & 45.7 \\
Market Value & 1.01 & 0.86 & 69.0 & & -0.01 & 0.00 & 47.1 \\
\hline
\end{tabular}

In Figure 1, I show how the distributions of acquirers and targets compare to the distribution of all firms in their respective industries. Specifically, I calculate the deciles of the firm size distribution (measured in sales) across all firms in each industry-year. ${ }^{11}$ I then count the proportion of acquirers and targets that fall into each decile. If transacting firms were distributed similarly to all firms, there would be about $10 \%$ of transacting firms in each decile, which is represented by the dashed line. Deciles above this line are overrepresented in that more than $10 \%$ of transacting firms are drawn from them, and deciles below the line are underrepresented. Examining first Panel A, acquirers, we see that the majority of acquirers come from the top deciles of their industries. The proportion of acquirers is monotonically increasing as we move up the deciles. The bottom 5 deciles are all underrepresented and the top 5 all overrepresented. The disparity is fairly large, from less than $6 \%$ in the bottom two deciles to almost $16 \%$ in the top. Turning to targets in Panel B, the results are quite different. Targets disproportionately come from the middle of the distribution, deciles 3 to 8 . Conditional on being in this group, they are spread fairly evenly, hovering between $10 \%$ and $12 \%$. Targets are underrepresented at both extremes, in deciles $1-2$ and 9-10. Even here, however, there is some activity. Figure 1 confirms that while acquirers tend to be large, targets do not tend to be small.

\subsubsection{Assortative Matching}

Table 2 revealed that acquirers tend to be considerably larger and more profitable than their targets. In this section, I show that a closer look at the data reveals an additional pattern, that is, the characteristics of acquirers and targets are highly correlated and display a good deal of positive assortative matching. In Table 4, I report the log correlations of the characteristics of acquirers and targets in individual matches. The first set of columns reports the correlations from the data as

\footnotetext{
${ }^{11}$ I focus on sales as the size metric as this gives the most available observations. The patterns shown are qualitatively similar no matter the size metric chosen.
} 


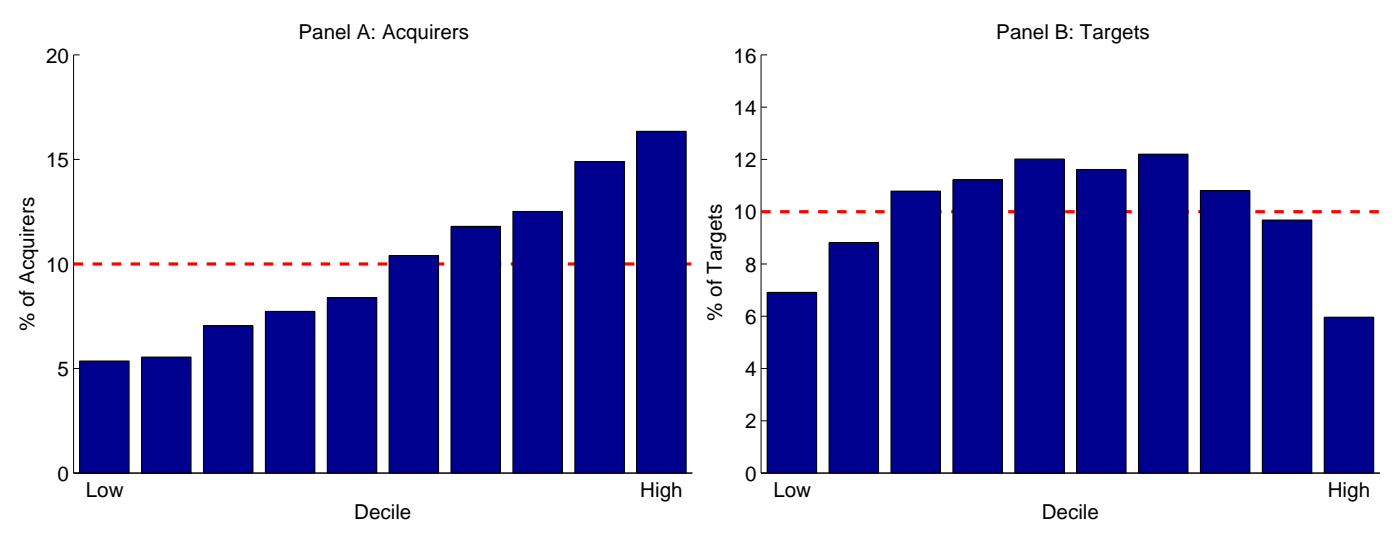

Figure 1: Decile Shares of Transacting Firms

reported and the second after rescaling by the industry medians. The results are striking. There is a large positive correlation between acquirers and targets along all dimensions of the data, on the order of about 0.6 . Although the magnitudes fall slightly, this pattern is robust to rescaling by industry medians.

In Figure 2, I show as an example the scatter plot of acquirer vs target sales. ${ }^{12}$ Each point in the figure represents one transaction. In Panel A, I show sales as reported. In Panel B, I show sales after rescaling by the industry median. There are about 12,000 transactions in the first panel and 4,500 in the second. To get a sense of the strength of the relationship, I include the linear regression line as well as the 45 degree line. The figure clearly illustrates the significant positive correlation between the two groups.

Table 4: Log Correlations of Acquirer and Target Characteristics

\begin{tabular}{lcc}
\hline & Reported & Scaled \\
\hline \hline Sales & 0.62 & 0.42 \\
Employment & 0.58 & 0.38 \\
PP\&E & 0.69 & 0.39 \\
EBITDA & 0.63 & 0.43 \\
Market Value & 0.64 & 0.48 \\
\hline
\end{tabular}

To further assess how matches are formed, Table 5 displays the joint distribution of acquirer and target sales. Specifically, I calculate the deciles over the distributions of sales for both acquirers and targets. I then sum the number of transactions in each joint decile of the two distributions. For example, the top left cell displays 535, which is the number of transactions in which both the acquirer and target are in the top deciles of their respective distributions. Finally, I bracket the cells containing the maximum number of transactions for each acquirer and target decile. Each bracketed cell then represents the maximum in a column or row, where the former is the largest

\footnotetext{
${ }^{12}$ Again, a similar figure is obtained when using any other size metric. My focus on sales is motivated by the number of observations available.
} 

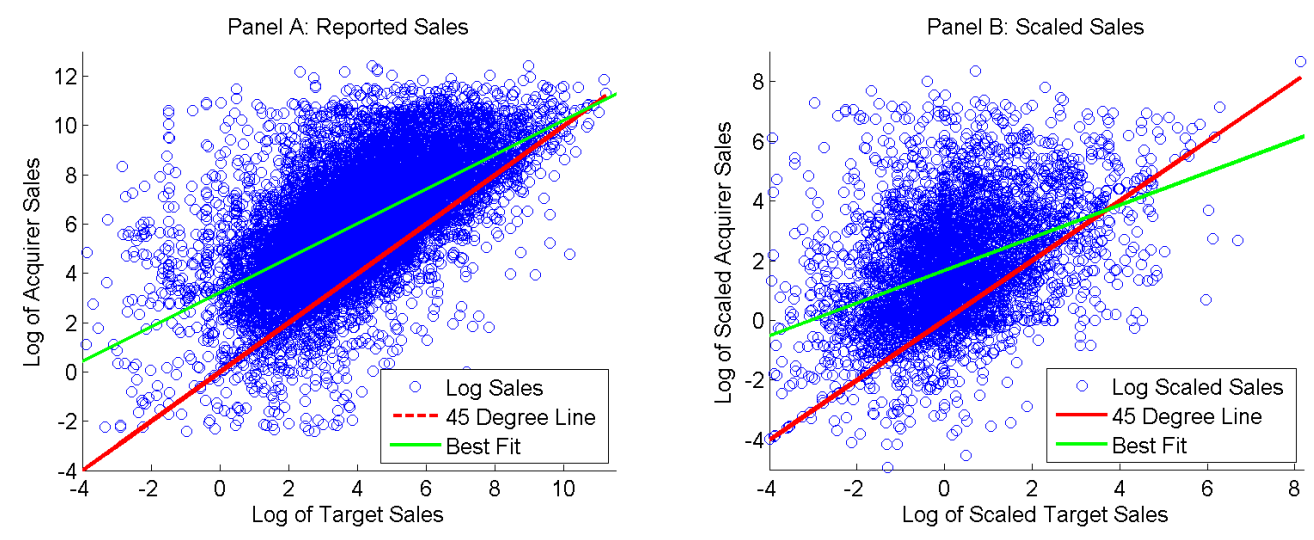

Figure 2: Acquirer vs Target Sales

target decile from which a given decile of acquirers draw their targets, and the latter the largest acquirer decile to which a given decile of targets sell. Perfectly assortative matching would imply that all bracketed cells lie on the diagonal of the matrix. The table clearly shows the large degree of positive sorting that occurs. For acquirers, the largest target decile is the same as their own in 6 out of 10 cases, and similarly, 7 out of 10 cases for targets. The remaining top deciles are all adjacent to the diagonal. Moreover, the numbers are generally decreasing as we move away from the diagonal in any direction. Thus, conditional on participating in the merger market, the largest acquirers tend to partner with the largest targets, and the smallest with the smallest. This fact is in line with Rhodes-Kropf and Robinson (2008), who discover a similar pattern when examining acquirer and target market-to book-ratios, and posit a resulting theory of synergistic mergers driven by asset complementarities.

Table 5: Joint Distribution of Acquirers and Targets

\begin{tabular}{c|ccccccccccc}
\hline Target Decile & \multicolumn{2}{c}{ Acquirer Decile $\longrightarrow$} \\
\hline$\downarrow$ & High & 9 & 8 & 7 & 6 & 5 & 4 & 3 & 2 & Low \\
\hline \hline High & 535 & 317 & 121 & 42 & 22 & 16 & 7 & 4 & 3 & 7 \\
9 & 268 & 293 & 218 & 149 & 102 & 22 & 14 & 5 & 10 & 6 \\
8 & 222 & 241 & 211 & 163 & 133 & 101 & 47 & 29 & 13 & 4 \\
7 & 141 & 197 & 196 & 201 & 183 & 117 & 98 & 40 & 36 & 17 \\
\cline { 3 - 11 } & 110 & 158 & 148 & 208 & 198 & 155 & 130 & 107 & 45 & 27 \\
5 & 65 & 105 & 127 & 170 & 165 & 187 & 164 & 127 & 87 & 47 \\
4 & 59 & 67 & 125 & 126 & 156 & 165 & 195 & 178 & 165 & 87 \\
3 & 60 & 44 & 77 & 97 & 122 & 164 & 184 & 191 & 216 & 164 \\
2 & 23 & 35 & 37 & 93 & 91 & 108 & 139 & 233 & 300 & 251 \\
Low & 35 & 23 & 39 & 49 & 42 & 91 & 108 & 144 & 254 & 433 \\
\hline
\end{tabular}




\subsection{The Role of Search}

As mentioned above, the corporate finance literature has increasingly recognized the potential importance of search in the M\&A market. Recent examples include Rhodes-Kropf and Robinson (2008) and Martos-Vila (2008). To get a sense of the mechanics of the M\&A market, Figure 3 outlines the process behind a typical acquisition as described in DePamphilis (2009). In brief, after deciding that an acquisition or merger is desirable and outlining the acquisition plan, i.e., the objectives for the transaction, firms begin the search for potential partners. Search is based on a number of criteria, and typically involves a lengthy and potentially costly process, entailing the use of databases, directories, and perhaps the hiring of expensive intermediaries such as investment banks and law firms. The list of candidate partners is narrowed through a screening process, and finally, contact is made and a potentially lengthy negotiation begins. If an agreement is reached, the deal is consummated. Otherwise, negotiations are broken off and the firms continue to search.

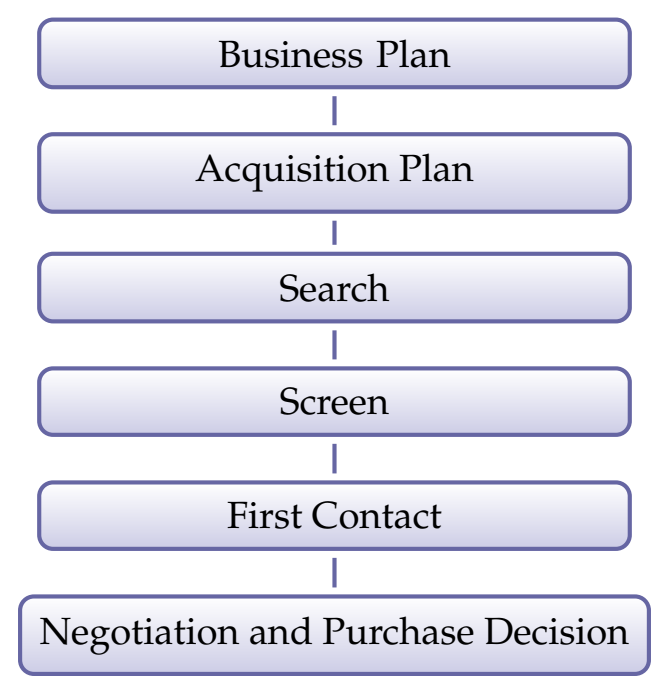

Figure 3: The Empirical Search Process

Boone and Mulherin (2007) describe a similar selling process. Firms typically make a strategic decision to search for a potential buyer. They proceed to contact bidders, either through an intermediary investment bank or directly. In the sample studied by Boone and Mulherin (2007), about half of firms contacted one bidder, while the other half contacted on average almost $21 .{ }^{13}$ After contact, interested bidders sign confidentiality agreements and perform due diligence. Finally, bids may be submitted. Some sellers may have proceeded with multiple acquirers and can choose between bids, and some have been negotiating with a single partner, and decide whether or not to accept the purchase offer.

The role of search and matching thus emerges quite clearly. The idea that firms decide if a merger is desirable, embark on a time-consuming and perhaps costly search process, select or

\footnotetext{
${ }^{13}$ Ultimately, this latter set of firms received bids from an average of only 1.57 interested purchasers.
} 
discard potential partners based on a number of criteria, and finally negotiate a mutually-agreed upon price leads quite naturally to a search and matching framework. Indeed, the M\&A market would seem a prime example of one that is not well described by the Walrasian benchmark of a centralized market. There are other features of the M\&A market that motivate a search and matching setup. Intermediaries, mainly in the form of investment banks, play an important role in connecting buyers and sellers. As we have seen, acquirers generally pay a significant premium over the target's current value, suggesting that the bilateral match has generated surplus to be shared.

\subsubsection{Repeat Acquisitions}

An important feature of the M\&A market is that acquiring firms are free to reenter the market following a completed transaction. This is in distinction to usual search markets, such as the labor market or the marriage market, in which it is difficult for an agent to form a new match without dissolving the old. Table 6 show the distribution of transactions by the number of times the acquirer has made an acquisition during the sample period. In only one-third of transactions is the acquirer a one-time purchaser. Indeed, there are only 28,945 unique acquirers across the 57,858 transactions. In about a quarter of transactions, the acquirer has made either 2 or 3 purchases, another quarter between 4 and 10, and the remainder more than 10. Thus, the acquisition-filled histories of Microsoft, Google, and Yahoo documented in the introduction are not anomalies, but rather, serial acquisition is quite common.

\begin{tabular}{ccc} 
Table 6: Transactions by Number of Acquirer Purch \\
\hline Acquirer Purchases & Transactions & Percent \\
\hline \hline 1 & 18,870 & 32.6 \\
$2-3$ & 13,301 & 23.0 \\
$4-5$ & 7,345 & 12.7 \\
$6-7$ & 4,695 & 8.1 \\
$8-10$ & 4,311 & 7.5 \\
$11-15$ & 4,251 & 7.3 \\
$16-20$ & 2,100 & 3.6 \\
$21-30$ & 1,914 & 3.3 \\
$31-40$ & 751 & 1.3 \\
More than 40 & 320 & 0.6 \\
\hline Total & 57,858 & 100.0 \\
\hline
\end{tabular}

\subsection{The Facts}

Before moving on to the model, I summarize the key empirical findings:

1. The majority of mergers are small, with a few very large transactions. 
2. The average merger premium is substantial.

3. Acquirers are typically larger and more profitable than their targets.

4. Acquirers tend to be the largest and most profitable firms; targets are not the smallest or least profitable.

5. There is significant positive correlation between the characteristics of acquirers and targets; observed transactions exhibit a large degree of positive assortative matching.

6. Firms must make a potentially costly and time-consuming search for potential partners; not all candidates are a good match and firms choose with which partners to proceed.

7. The majority of acquirers make multiple purchases on the merger market.

\section{The Model}

In this section I present a model of merger activity in a dynamic general equilibrium setting. The active agents in the model are a set of heterogeneous firms operating in a monopolistically competitive differentiated goods industry. Firms offer a product portfolio composed of a bundle of individual varieties. In addition to hiring labor, producing output, and reaping profits, firms act in a merger market, in which they can buy other firms and expand, or sell themselves and exit the industry. Mergers give firms the opportunity to incorporate new varieties and enhance their product portfolio. Following a merger, the productivity of the acquiring firm evolves as an aggregate over those of the two pre-merger firms. The acquirer then continues on in production, and importantly, retains the option of participating again in the merger market.

In line with the empirical merger process described above, the merger market is characterized by search and matching frictions. Firms must make a costly investment in search which gives a Poisson arrival of meeting a prospective partner. Upon meeting, firms bargain over the purchase price and choose to consummate some transactions and reject others. There is endogenous entry into the industry subject to a setup cost. The prospects of participating in the merger market along with the general equilibrium effects of merger activity on industry aggregates influence firm entry and exit decisions. Thus, merger activity affects aggregate industry performance by redistributing resources across operating firms and changing the dynamic incentives for entry and exit. I will focus on a stationary equilibrium in which individual firms are constantly entering, exiting and merging, but the economy replicates itself in such a way as to keep aggregate variables constant.

\subsection{Preferences and Final Production}

Time is continuous and indexed by $\tau .^{14}$ The economy is populated by a constant measure $L$ of identical consumers. Consumers inelastically supply labor and have preferences of the form

$$
\int_{0}^{\infty} e^{-\kappa \tau} \log \left(C_{\tau}\right) d \tau
$$

\footnotetext{
${ }^{14}$ The focus on a stationary equilibrium will obviate the need to track time and henceforth I suppress time subscripts.
} 
where $C_{\tau}$ denotes time $\tau$ consumption of a final good, described below, and $\kappa>0$ is the rate of time discount. In a stationary equilibrium, this gives rise to a constant real interest rate given by $r=\kappa$.

The final good is produced by competitive firms from a continuum of differentiated intermediate goods, indexed by $\omega$. Final good producers operate with a constant returns to scale CES production technology of the form:

$$
Y=\left[\int_{\omega \in \Omega} q(\omega)^{\rho} d \omega\right]^{\frac{1}{\rho}}
$$

where $\Omega$ denotes the set of intermediate products and $0<\rho<1$ such that the products are substitutes with associated elasticity of substitution $\sigma=\frac{1}{1-\rho}>1$. Standard arguments give the aggregate price index

$$
P=\left[\int_{\omega \in \Omega} p(\omega)^{1-\sigma} d \omega\right]^{\frac{1}{1-\sigma}}
$$

and demand and expenditure functions for each product

$$
q(\omega)=Y\left[\frac{p(\omega)}{P}\right]^{-\sigma}, r(\omega)=R\left[\frac{p(\omega)}{P}\right]^{1-\sigma}
$$

where $R=P Y$ denotes aggregate expenditure on the final good.

\subsection{Intermediate Production}

A continuum of monopolistically competitive firms operate with heterogeneous productivities $\tilde{z}$ to produce the set of intermediate products $\Omega$. Firms may offer multiple products as they add varieties through acquisition. For convenience, I assume that a firm is characterized by a single productivity level that is applicable to all of its products. Then, we can think of each firm as offering a single product portfolio composed of a bundle of individual varieties. ${ }^{15}$ In a process to be described below, the firm's productivity $\tilde{z}$ may evolve as the firm grows through acquisition. Thus, despite the absence of productivity shocks subsequent to entry, the firm's productivity level is in part endogenous and determined by its outcomes on the merger market, as is the size of its product portfolio.

Labor is the only factor of production and the wage $w$ is normalized to 1 and serves as numeraire. For each product $j$ produced by a $k$-product firm with productivity $\tilde{z}$, the production technology exhibits constant returns to scale in labor and takes the form $q_{j}(\tilde{z})=\tilde{z}^{\frac{1}{\sigma-1}} l_{j}$. I follow Atkeson and Burstein (2010) in rescaling $\tilde{z}$ by the exponent $\frac{1}{\sigma-1}$, which implies that firm revenues, labor demand, and variable profits are proportional to $\tilde{z}$. This will prove convenient in generating a particularly simple interaction between the number of products in a firm's product portfolio $k$

\footnotetext{
${ }^{15}$ The idea that the firm has a single productivity level for all products nests the case in which each product retains an individual productivity level in a straightforward manner.
} 
and its productivity $\tilde{z}$, greatly easing the computation of the model.

The total output of a $k$-product firm with productivity $\tilde{z}$ is then

$$
q(k, \tilde{z})=\sum_{j=1}^{k} \tilde{z}^{\frac{1}{\sigma-1}} l_{j}=k \tilde{z}^{\frac{1}{\sigma-1}} l_{j}
$$

where I have used the fact that product-level production labor $l_{j}$ is determined by the firm's common productivity level $\tilde{z}$ and so will be identical across all of its products. We can see that $\tilde{z}^{\frac{1}{\sigma-1}}$ represents the per-product productivity of the firm and total output will scale with the size of the firm's product portfolio, measured by the number of products it offers.

Standard arguments give the common output price set by the firm for each of its products as

$$
p(\tilde{z})=\frac{1}{\rho \tilde{z}^{\frac{1}{\sigma-1}}}
$$

In order to produce and remain in the industry, firms must pay a fixed cost of operation of $c_{f}$ units of the final good. It is straightforward to show that labor demand, revenues, and variable profits from sales net of fixed costs for a $k$-product firm are then equal to

$$
\begin{aligned}
l(k, \tilde{z}) & =\rho^{\sigma} R P^{\sigma-1} k \tilde{z} \\
r(k, \tilde{z}) & =R(\rho P)^{\sigma-1} k \tilde{z} \\
\pi(k, \tilde{z}) & =\frac{R}{\sigma}(\rho P)^{\sigma-1} k \tilde{z}-P c_{f}
\end{aligned}
$$

An important implication of the production technology is that the number of products a firm offers and its physical productivity enter everywhere multiplicatively into its product market outcomes. Defining an index $z=k \tilde{z}$, we have

$$
\begin{aligned}
l(z) & =\rho^{\sigma} R P^{\sigma-1} z \\
r(z) & =R(\rho P)^{\sigma-1} z \\
\pi(z) & =\frac{R}{\sigma}(\rho P)^{\sigma-1} z-P c_{f}
\end{aligned}
$$

such that $z$ represents a sufficient statistic for firm profits and size. As we will see below, all decisions of the firm can be determined by its $z$ and the relevant economic aggregates, so that the firm's individual state has been reduced to one dimension. Additionally, I will show that the aggregates themselves can be determined by the distribution of $z$, and hence do not require tracking the joint distribution of $k$ and $\tilde{z}$. I will call $z$ "effective productivity," since it is this combination of $k$ and $\tilde{z}$ that effectively determine the firm's size and profitability. Intuitively, firm outcomes are determined by both the size of its product suite and its level of productive efficiency. The ratio of any two firms' labor demand, revenues and variable profits (gross of fixed costs) is equal to $\frac{z_{1}}{z_{2}}$. Henceforth, we can treat our multi-product firms as offering only a single product, which we 
know to be composed of a bundle of individual varieties, with effective productivity $z .^{16}$

\subsection{The Merger Market}

In addition to hiring labor, producing, and reaping profits on the output market, firms can participate in a merger market, in which the firms themselves represent products to be bought and sold. Firms enter the merger market in order to trade the blueprints or knowledge to produce a product or suite of products (an alternative interpretation would be the team of assembled labor with the particular expertise to manufacture these products). After a merger takes place, the acquirer incorporates the products formerly held by the target into its portfolio, pays a one-time acquisition price to the selling firm, and continues on in production. Target firms sell their suite of products, receive the merger payment from the purchasing firm, and exit the market. Importantly, acquirers retain the option to participate in the merger market after a transaction occurs, that is, once a transaction is concluded, the continuing firm is free to pursue more opportunities on the merger market.

\subsubsection{Merger Technology}

Upon merger, the characteristics of the acquiring firm evolve as a function of the characteristics of the two pre-merger firms. In particular, the effective productivity of the post-merger entity $z_{m}$ is determined as an aggregate over those of the pre-merger acquirer and target, $z_{a}$ and $z_{t}$, according to the following CES merger technology:

$$
z_{m}=s\left(z_{a}, z_{t}\right)=A\left[\alpha z_{a}^{\gamma}+(1-\alpha) z_{t}^{\gamma}\right]^{\frac{v}{\gamma}}
$$

It is intuitive that the effective productivity of the new entity depends on those of the two premerger firms. This captures the idea that the size and efficiency of the pre-merger firms jointly determine the outcome from merger. In practicality, the acquiring firm is bundling formerly separate streams of revenues and profits, which we have seen depend on the individual firms' effective productivities. The parameters of the merger technology can be interpreted analogously to their role in a CES production function. $\gamma$ determines the substitutability between $z_{a}$ and $z_{t}, v$ governs the returns to scale of the technology, $\alpha$ is a weighting factor, and $A$ allows for some degree of autonomous change from merger, independent of $z_{a}$ and $z_{t}$.

Recall that the firm's effective productivity $z$ is composed of the size of its product base $k$ and its physical productivity $z$. Because mergers do not result in the creation (or destruction) of products, we have that $k_{m}=k_{a}+k_{t}$, i.e., the merged firm's portfolio is the sum over those of the two pre-merger firms. Then the evolution of $z$ is such that (7) holds. This technology is convenient in providing a good deal of flexibility in modeling the transformation from two pre-merger firms

\footnotetext{
${ }^{16}$ In the Appendix, I develop a version of the model using a single homogenous good and decreasing returns to scale in production a la Lucas span of control. This version of the model gives identical implications, while eliminating the need to track the size of the firm's product portfolio.
} 
to a single post-merger entity. Below, I consider in detail a number of particular technologies that are nested inside the CES specification and I defer further discussion until then.

\subsubsection{Search Technology}

In line with with the empirical transaction process outlined above, the merger market is characterized by search and matching frictions. The search market here is not two-sided in the standard sense of having two disjoint types seeking to match, as is the case in the labor market with firms and workers or the marriage market with men and women. Rather, firms are searching for one another and may end up on either side of a transaction. To capture this idea, firms are able to search simultaneously on both sides of the market, although their search intensities and rate of transaction are endogenous and depend on their expected surplus from each type of match.

Firms choose search intensities $\lambda(z)$ of meeting a potential target and $\mu(z)$ of meeting a potential acquirer. To obtain these intensities, the firm must expend $C_{\lambda}(\lambda)$ units of the final good in seeking potential targets and $C_{\mu}(\mu)$ in seeking potential purchasers. $C_{x}(x)$ is convex and satisfies the standard properties $C_{x}(0)=0, C_{x}^{\prime}(x)>0, C_{x}^{\prime \prime}(x)>0, \lim _{x \rightarrow \infty} C_{x}(x)=\infty$ for $x=\lambda$, $\mu$. Denote by $d G(z)$ the endogenous distribution of firm types in the market, which will be described below. The individual search decisions of the firms in the market generate aggregate search intensities $\int \lambda(z) d G(z)$ and $\int \mu(z) d G(z)$. In a bit of a technicality, it is possible that there is rationing in equilibrium if the aggregate search intensities do not equate, leaving some searchers on the long side of the market unrewarded by a meeting. ${ }^{17}$ The aggregate meeting rate takes the form

$$
\min \left\{\int \lambda(z) d G(z), \int \mu(z) d G(z)\right\}
$$

With possible rationing, to obtain the effective meeting rates, search intensities must be be scaled by a proportion factor representing the probability of a meeting per unit of search. These factors take the form

$$
\begin{aligned}
& j_{a}=\min \left\{\frac{\int \mu(z) d G(z)}{\int \lambda(z) d G(z)}, 1\right\} \\
& j_{t}=\min \left\{\frac{\int \lambda(z) d G(z)}{\int \mu(z) d G(z)}, 1\right\}
\end{aligned}
$$

for acquirers and targets, respectively.

A type $z_{a}$ acquirer finds a type $z_{t}$ target according to a Poisson arrival rate

$$
\frac{\lambda\left(z_{a}\right) j_{a} \mu\left(z_{t}\right) d G\left(z_{t}\right)}{\int \mu(z) d G(z)}=\lambda\left(z_{a}\right) j_{a} \Gamma\left(z_{t}\right) d G\left(z_{t}\right)
$$

\footnotetext{
${ }^{17}$ We will see in the numerical analysis that this form of rationing does not seem to play an important role in US M\&A activity.
} 
Similarly, this target finds this acquirer at rate

$$
\frac{\mu\left(z_{t}\right) j_{t} \lambda\left(z_{a}\right) d G\left(z_{a}\right)}{\int \lambda(z) d G(z)}=\mu\left(z_{t}\right) j_{t} \Lambda\left(z_{a}\right) d G\left(z_{a}\right)
$$

where $\Gamma\left(z_{t}\right)$ and $\Lambda\left(z_{a}\right)$ denote the conditional probability (upon some meeting) of meeting a particular target and acquirer, respectively.

Once firms meet a candidate partner, they will assess the characteristics of that partner and choose to either consummate the transaction or reject that particular match and continue operating in their current state. Thus, the firm has two decisions to make in the merger market: first, with what intensity to search for potential partners on each side of the market, and second, whether to complete a deal once a potential match has been formed.

\subsubsection{Bargaining}

Upon meeting, the net surplus generated by proceeding with a merger is

$$
\Sigma\left(z_{a}, z_{t}\right)=V\left(z_{m}\right)-V\left(z_{a}\right)-V\left(z_{t}\right)
$$

where $V\left(z_{m}\right)$ denotes the value of the post-merger entity, $V\left(z_{a}\right)$ the value of the pre-merger acquirer and similarly $V\left(z_{t}\right)$ for the pre-merger target. Intuitively, the surplus is simply the value of the merged entity less the sum of the values of the two parties as standalone firms. The firms will consummate a merger when $\Sigma\left(z_{a}, z_{t}\right) \geq 0$, i.e., whenever the value of the post-merger firm is at least as large as the sum of the values of the pre-merger firms. Once a match is formed, the surplus must be divided between the two parties. Bargaining occurs according to the generalized Nash bargaining protocol and results in a commonly agreed upon purchase price $P\left(z_{a}, z_{t}\right)$. Denoting with $\beta$ the bargaining power of the acquirer, the purchase price satisfies

$$
\begin{aligned}
P\left(z_{a}, z_{t}\right) & =V\left(z_{t}\right)+(1-\beta)\left(\Sigma\left(z_{a}, z_{t}\right)\right) \\
& =V\left(z_{t}\right)+(1-\beta)\left(V\left(z_{m}\right)-V\left(z_{a}\right)-V\left(z_{t}\right)\right)
\end{aligned}
$$

where $1-\beta$ denotes the target bargaining weight. Intuitively, the purchase price reflects both the outside option of the target, which is to continue as a standalone entity, as well as the target's share of the net surplus generated by the merger. The merger premium is easily shown to satisfy

$$
\frac{P\left(z_{a}, z_{t}\right)-V\left(z_{t}\right)}{V\left(z_{t}\right)}=\frac{(1-\beta)\left(V\left(z_{m}\right)-V\left(z_{a}\right)-V\left(z_{t}\right)\right)}{V\left(z_{t}\right)}
$$

The premium in each merger depends on the bargaining shares of the two parties as well as the net gains generated. Recall from Table 1 that the observed premia are substantial.

I illustrate the timing of the merger market in Figure 4. 


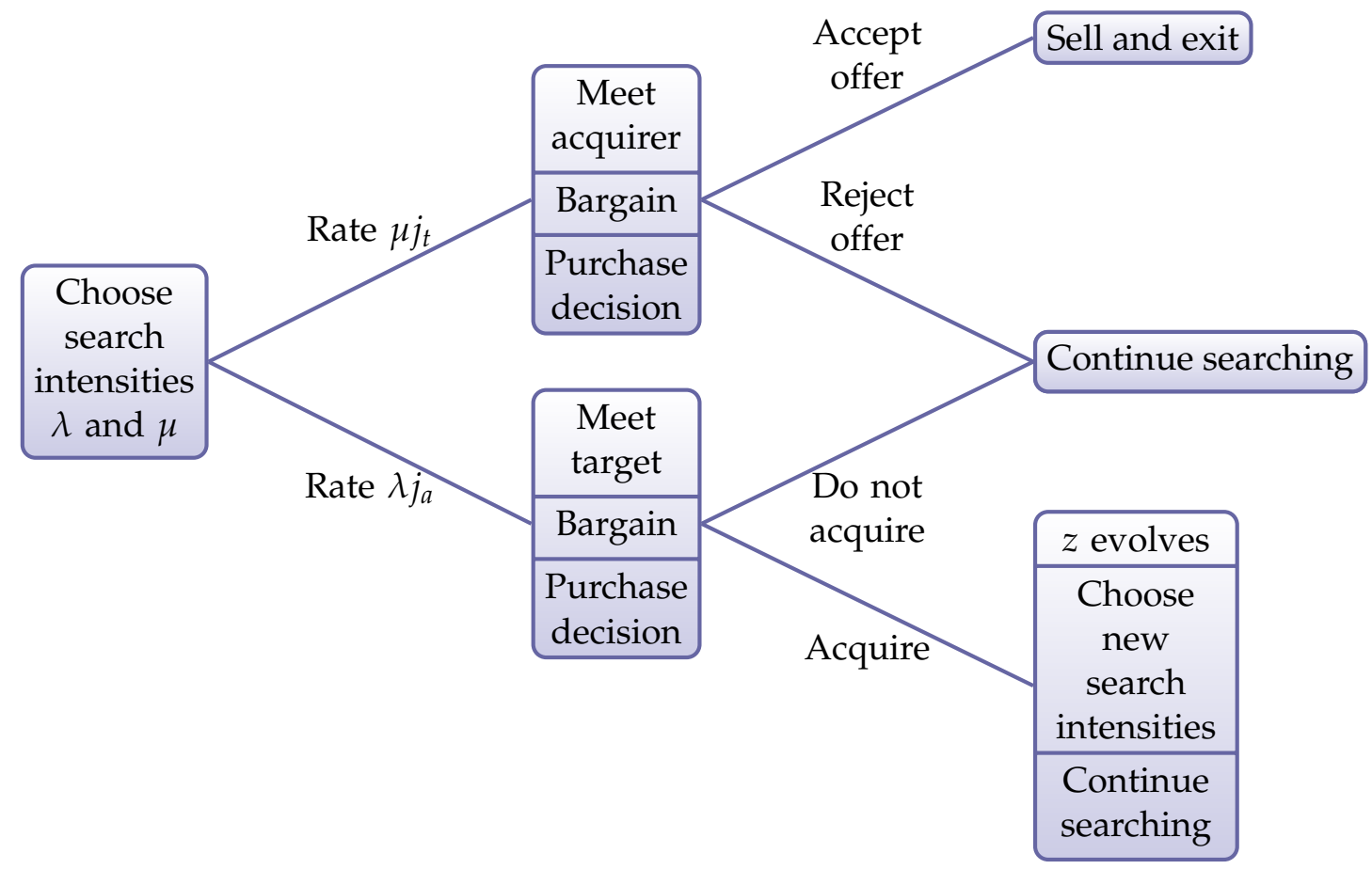

Figure 4: The Timing of Actions on the Merger Market

\subsection{Entry and Exit}

The industry is characterized by free entry. There is a large pool of ex-ante identical potential entrants. To enter, firms must expend $c_{e}$ units of the final good to obtain a draw from an exogenous distribution $F(z), z \in\left(z_{\min }, \infty\right)$ with associated density function $d F(z){ }^{18}$

Once an entrant realizes its initial $z$, it may enter the market and begin operations, or exit immediately. The fixed cost of operation $c_{f}$ implies that some firms may draw a low enough $z$ such that the value from entering is negative. The entry decision will be determined by a threshold value $\hat{z}$ defined implicitly by $V(\hat{z})=0$, such that firms drawing $z<\hat{z}$ will choose not to enter. Intuitively, firms will enter as long as there is positive value from doing so. Upon entry, the firm's value depends on its profit flows as well as its prospects in the merger market. Thus, the existence of the merger market will influence the entry threshold both by affecting the industry aggregates that in part determine firm profits and by giving firms an additional value stream stemming from expected gains in the merger market.

The free entry condition requires

$$
\int V(z) d F(z) \leq P c_{e}
$$

\footnotetext{
${ }^{18}$ For simplicity, I assume draws from the entry distribution include both an initial productivity level and an initial number of products, so that firms draw a $z$ directly. Alternatively, we can think of firms as drawing only a random productivity level and beginning with only a single product so that firms are drawing a $\tilde{z}$. Of course, this just means that $z=\tilde{z}$ for the new entrant, and other than complicating notation, has no other implications.
} 
i.e., that the expected value of entry is less than or equal to the cost, with equality if there is positive entry in equilibrium.

Following entry, firms are subject to an exogenous common exit shock that arrives at rate $\delta$. However, there are actually several reasons exit may occur, and exit rates may vary systematically across the range of firms in the economy. First, for firms that draw a $z \leq \hat{z}$, exit is immediate. For firms that choose to enter, exit can occur either through the realization of the exogenous shock $\delta$, or by being acquired. The rate of exit for an incumbent firm of type $z$ is then given by

$$
\delta+\mu(z) j_{t} \int \Phi\left(\Sigma\left(z_{a}, z\right)\right) \Lambda\left(z_{a}\right) d G\left(z_{a}\right)
$$

where the latter term is the rate at which this firm type is acquired, composed of the product of the meeting rate and the conditional probability that a transaction is consummated. This last is the integral over the set of firm types that result in positive surplus, weighted by the endogenous distribution of firms types scaled by their search intensity as acquirers. The weights represent the endogenous presence of each firm type on the acquiring side of the market. $\Phi(\cdot)$ denotes the indicator function equal to 1 if its argument is greater than or equal to zero, else equal to zero. Consistent with well-known empirical facts, new entrants will have a higher rate of exit than incumbents. Within the set of incumbent firms, exit rates will vary systematically to the extent that the rate of being acquired does.

\subsection{Value Functions and Decision Rules}

Having defined the environment and the firm's decision problem, we can write the continuous time value function of an incumbent firm in stationary equilibrium as

$$
\begin{aligned}
(r+\delta) V(z) & =\pi(z)-P C_{\lambda}(\lambda(z))-P C_{\mu}(\mu(z)) \\
& +\lambda(z) j_{a} \int \max \left\{V\left(z_{m}\left(z, z_{t}\right)\right)-V(z)-P\left(z, z_{t}\right), 0\right\} \Gamma\left(z_{t}\right) d G\left(z_{t}\right) \\
& +\mu(z) j_{t} \int \max \left\{P\left(z_{a}, z\right)-V(z), 0\right\} \Lambda\left(z_{a}\right) d G\left(z_{a}\right)
\end{aligned}
$$

The first line represents the net profit flows of the firm, composed of profits from the output market, which are net of fixed costs, less the cost of search on the merger market. The second line represents the value from being a potential acquirer on the merger market. The firm meets a candidate target at rate $\lambda j_{a}$. The target is drawn randomly from the set of operating firms with probabilities depending on the endogenous distribution of firm types $d G(z)$ and the search intensities of the firms on the target side of the market. The firm then decides whether to consummate the transaction, giving capital gains equal to the value of the new post-merger entity less the value of the existing firm that is lost and the purchase price paid to the target, or reject the match and continue on as a standalone entity, giving capital gains of zero. Similarly, the last line denotes the value from being a potential target and is interpreted analogously. Here, the capital gain from a 
completed transaction is the price received less the value of continuing as-is.

After imposing the Nash bargaining solution (13), which implies that the surplus generated from merger is distributed to the transacting firms according to their respective bargaining weights, we can rewrite the value function as

$$
\begin{aligned}
(r+\delta) V(z) & =\pi(z)-P C_{\lambda}(\lambda(z))-P C_{\mu}(\mu(z)) \\
& +\lambda(z) j_{a} \beta \int \max \left\{\Sigma\left(z, z_{t}\right), 0\right\} \Gamma\left(z_{t}\right) d G\left(z_{t}\right) \\
& +\mu(z) j_{t}(1-\beta) \int \max \left\{\Sigma\left(z_{a}, z\right), 0\right\} \Lambda\left(z_{a}\right) d G\left(z_{a}\right)
\end{aligned}
$$

where the firm's expected gains in the merger market are now functions of the bargaining shares and the expected net surplus created from a match.

For ease of exposition, I define

$$
\begin{aligned}
E\left[M_{a}(z)\right] & =\beta \int \max \left\{\Sigma\left(z, z_{t}\right), 0\right\} \Gamma\left(z_{t}\right) d G\left(z_{t}\right) \\
E\left[M_{t}(z)\right] & =(1-\beta) \int \max \left\{\Sigma\left(z_{a}, z\right), 0\right\} \Lambda\left(z_{a}\right) d G\left(z_{a}\right)
\end{aligned}
$$

as the expected capital gains from meeting a candidate partner as an acquirer and target, respectively, conditional on a potential match having been formed. The value function is then simply

$$
(r+\delta) V(z)=\pi(z)-P C_{\lambda}(\lambda(z))-P C_{\mu}(\mu(z))+\lambda j_{a} E\left[M_{a}(z)\right]+\mu(z) j_{t} E\left[M_{t}(z)\right]
$$

The firm makes two types of decisions in the merger market. The first is to choose a pair of search intensities with which to seek potential targets and potential purchasers. Optimal search is governed by a pair of first order conditions:

$$
\begin{aligned}
P C_{\lambda}^{\prime}(\lambda(z)) & =j_{a} E\left[M_{a}(z)\right] \\
P C_{\mu}^{\prime}(\mu(z)) & =j_{t} E\left[M_{t}(z)\right]
\end{aligned}
$$

Intuitively, firms choose search intensities that equate the marginal costs of search to the expected marginal gains. This latter is composed of the additional probability of meeting a potential partner multiplied by the expected gain conditional on having formed a potential match.

Once the firm meets a candidate partner, it has the choice of whether to consummate the merger or proceed as a standalone entity. As shown above, there is a common acceptance set for acquirers and targets in which any transaction generating positive surplus is consummated, i.e., while $\Sigma\left(z_{a}, z_{t}\right) \geq 0$. The firm's decision rule is characterized by two acceptance regions, the first representing the set of targets it is willing to purchase and the second the set of acquirers it is 
willing to sell itself to. Formally, I define these regions by

$$
\begin{aligned}
Y_{t}(z) & =\left\{z_{t}: \Sigma\left(z, z_{t}\right) \geq 0\right\} \\
Y_{a}(z) & =\left\{z_{a}: \Sigma\left(z_{a}, z\right) \geq 0\right\}
\end{aligned}
$$

Finally, the entry decision is characterized by a threshold $\hat{z}$ where firms drawing $z<\hat{z}$ will choose to exit the industry immediately and firms with $z \geq \hat{z}$ will choose to enter. The threshold is implicitly defined where the value of operation is exactly zero, i.e., $V(\hat{z})=0$. From the firm's value function (18), we see

$$
\begin{aligned}
V(\hat{z}) & =0 \\
\Rightarrow \pi(\hat{z}) & =-\left\{\lambda(\hat{z}) j_{a} E\left[M_{a}(\hat{z})\right]+\mu(\hat{z}) j_{t} E\left[M_{t}(\hat{z})\right]-P C_{\lambda}(\lambda(\hat{z}))-P C_{\mu}(\mu(\hat{z}))\right\}
\end{aligned}
$$

Intuitively, the cutoff productivity is set where the firm's profit flows from the output market (net of fixed costs) equals the negative of its expected gains from participating in the merger market. Expected gains in the merger market must be nonnegative, else the firm would optimally choose not to participate in this market at all. Thus, (21) reveals that a firm with the cutoff productivity $\hat{z}$ will actually incur negative profits as long as there is any positive value from its prospects in the merger market. Without the possibility of merger, the right hand side of (21) would be zero, i.e., the cutoff productivity would be where flow profits are exactly zero. Here, the threshold is lower. Less productive firms are willing to enter the market and incur losses simply to retain the option value of participating in the merger market. Seen another way, once a firm has paid the sunk cost of entry, the prospects of merging make it more reluctant to exit.

Note, however, that this does not necessarily imply that the threshold is lower than in an economy without mergers. The entry decision also depends upon the level of flow profits, which are a function of the industry aggregates. By redistributing resources across firms, the merger market influences industry performance and thus the aggregates that enter the profit function. If the merger process generates aggregates that induce lower levels of flow profits, then the merger market may actually raise the entry threshold, resulting in increased selection at the entry margin. Thus, the effect of mergers on the entry decision is ambiguous, and depends upon the rate at which individual profits fall due to the greater efficiency of the industry versus the rate at which the potential gains from merger add to the marginal firm's value (in other words, whether the left hand side of (21) falls faster or slower than the absolute value of the right hand side increases).

\subsection{Stationary Equilibrium}

In a stationary equilibrium, the economy replicates itself such that the aggregate variables remain constant. This implies that the inflows and outflows of firms in the market must balance for all 
firm types. The stationary conditions for each individual type $z$ take the form

$$
\begin{aligned}
& M \int \lambda\left(z_{a}\right) j_{a}\left[\int_{s^{-1}\left(z, z_{a}\right)} \Phi\left(\Sigma\left(z_{a}, z_{t}\right)\right) \Gamma\left(z_{t}\right) d G\left(z_{t}\right)\right] d G\left(z_{a}\right)+M_{e} d F(z) \\
= & \lambda(z) j_{a} M d G(z) \int \Phi\left(\Sigma\left(z, z_{t}\right)\right) \Gamma\left(z_{t}\right) d G\left(z_{t}\right) \\
+ & \mu(z) j_{t} M d G(z) \int \Phi\left(\Sigma\left(z_{a}, z\right)\right) \Lambda\left(z_{a}\right) d G\left(z_{a}\right)+\delta M d G(z) \forall z \geq \hat{z}
\end{aligned}
$$

where $s^{-1}\left(z, z_{a}\right)=\left\{z_{t}: s\left(z_{a}, z_{t}\right)=z\right\}$ denotes the inverse of the merger technology defined in (7). For each type, firms flow in as the continuing entity generated from a merger that moves the post-merger firm into that type $z$ and through new entry. Firms flow out through participation in a merger, either as an acquirer or target, and through the realization of the exogenous exit shock. Integrating both sides, we find the aggregate stationary condition

$$
[1-F(\hat{z})] M_{e}=\left\{\delta+\int \mu(z) j_{t}\left[\int \Phi\left(\Sigma\left(z_{a}, z\right)\right) \Lambda\left(z_{a}\right) d G\left(z_{a}\right)\right] d G(z)\right\} M
$$

which requires that the total flow of firms into the market must equal the total flow of firms out, where the latter is the integral over the exit rates defined in (16).

There are two feasibility constraints in the economy. First, labor market clearing requires

$$
M \int l(z) d G(z)=L
$$

i.e., that demand and supply for labor equate. For the final good, feasibility requires

$$
Y=C+Y_{s}+Y_{f}+Y_{e}
$$

where

$$
Y_{s}=M\left[\int C_{\lambda}(\lambda(z)) d G(z)+\int C_{\mu}(\mu(z)) d G(z)\right]
$$

denotes the total resources devoted to search activities on the merger market, $Y_{f}=M c_{f}$ resources devoted to the fixed costs of production, and $Y_{e}=M_{e} c_{e}$ resources devoted to the creation of new firms. That is, final production is allocated to final consumption and to payment of the various resource costs in the economy.

We are now in a position to define an equilibrium in this economy.

Definition (Equilibrium). A stationary search equilibrium consists of

1. aggregate variables $\left\{Y, P, C, M, M_{\mathcal{e}}, d G(z)\right\}$

2. intermediate good prices and quantities, entry threshold, and values $\{p(z), q(z), \hat{z}, V(z)\}$

3. firm search intensities and acceptance sets on the merger market $\left\{\lambda(z), \mu(z), Y_{t}(z), Y_{a}(z)\right\}$ such that 
1. consumers maximize utility

2. intermediate and final goods firms maximize expected discounted profits

3. the labor market and final good market feasibility constraints are satisfied

4. the evolution of firm types is consistent with the stationary conditions.

\subsection{Aggregation}

Despite the complexity of the environment, the model aggregates in a simple manner. Defining an index of productivity across firms

$$
\bar{Z}=\int_{\hat{z}}^{\infty} z d G(z)
$$

it is straightforward to show that aggregate prices, output, and productivity satisfy

$$
\begin{aligned}
P & =\frac{1}{\rho}(M \bar{Z})^{\frac{1}{1-\sigma}} \\
Y & =(M \bar{Z})^{\frac{1}{\sigma-1}} L \\
T F P & =(M \bar{Z})^{\frac{1}{\sigma-1}}
\end{aligned}
$$

Thus, the impact of M\&A on aggregate performance can be summarized through its influence on $M$ and $\bar{Z}$. Notice that the sufficiency of $z$ in characterizing individual outcomes holds in the aggregate as well. Aggregate prices, output and productivity respond equally to an increase in the mass of firms $M$ and in the productivity index $\bar{Z}$. Indeed, once these variables are determined, the economy performs as one with a representative firm with productivity equal to TFP as defined in (26). The existence of the merger market endogenizes the components of TFP and determines aggregate performance by affecting both the mass of firms, and the productivity index through the distribution of resources across operating firms $d G(z)$ and the threshold productivity level $\hat{z}$.

Turning to the consumer side, recall from (25) that final consumption is equal to final output less the resources devoted to the fixed costs of production, search on the merger market, and the creation of new firms. Given aggregate output $Y$ and an allocation of resources across these uses, we can then evaluate final consumption and welfare. To the extent that the amount of resources absorbed by non-consumption activities changes due to M\&A activity, consumer outcomes may move differently than industrial outcomes such as output and productivity. I quantitatively explore the impact of M\&A on aggregate outcomes in a calibrated economy below.

\subsection{Implications of Merger Theories}

The model does not in general yield analytic solutions. It is possible, however, to characterize the predicted matching patterns under some particular specifications of the merger technology. In this section, I use the theoretical framework to evaluate the implications of several existing theories of merger activity. In particular, I analyze the merger market outcomes predicted by these theories 
and assess their consistency with the stylized facts. We will see that each meets some significant difficulties in matching the full set of empirical merger patterns described above.

What are the incentives to merge in the model? Depending on the specification of the merger technology, there may be three. First, there is a fixed cost saving. Following a merger, the continuing firm has bundled the products of the pre-merger firms, but need only pay the fixed cost of production once. Second, there may be q-related incentives, i.e., the productivity of the acquired resources may increase following acquisition, generating surplus and an incentive for firms of differing productivities to transact. Finally, to the extent that the evolution of the acquiring firm's productivity depends positively on both the pre-merger entities, there may be complementarities, or synergies, in the sense that two like firms coming together generates something more than the sum of the individual parts. I will address each of these theories in turn and show that none alone can explain the merger patterns observed in the data.

I begin with a theory of scale efficiencies through fixed cost savings. Under this theory, there are no particular gains from the bundling of products and but for the fixed cost, two standalone firms generate the same profit flows as the combined entity. Because the profit functions are linear in $z$, this theory of no gains from bundling implies a technology of the form $z_{m}=z_{a}+z_{t}$, a case that is nested in (7) by setting $\gamma=1, v=1, \alpha=\frac{1}{2}, A=2$, corresponding to the typical case of perfect substitutes. Intuitively, the combination of firms used to produce a particular $z_{m}$ is irrelevant. Substituting for $z=k \tilde{z}$, it is straightforward to show that this technology implies an evolution for the firm's physical productivity of $\tilde{z}_{m}=\frac{k_{a}}{k_{a}+k_{t}} \tilde{z}_{a}+\frac{k_{t}}{k_{a}+k_{t}} \tilde{z}_{t}$, i.e., the merged firm takes on a productivity level that is simply a weighted average of the two pre-merger firms, where the weights are equal to each firm's share of the total number of products transacted. This technology seems a natural starting point to consider the implications of various technologies for merger patterns. Under this theory of the merger technology, the following proposition, which I prove in the Appendix, holds:

Proposition 1. If the merger technology exhibits no gains from bundling, i.e., $z_{m}=z_{a}+z_{t}$, (i) all meetings will result in merger, (ii) the correlation between the characteristics of targets and acquirers will be zero, (iii) the mean and median difference between targets and acquirers will be zero, and (iv) the median target and the median acquirer will be the same as the median firm.

The intuition here is clear. Absent gains from bundling, no additional surplus is generated from any particular combination of products, and the gains from merger are constant across all possible meetings. Firms choose identical search intensities and will merge with any partner upon meeting. The proposition is then immediate. Recall that the observed merger patterns exhibit high correlation between targets and acquirers, that acquirers are generally significantly larger than their targets, and that the mean and median acquirer is considerably larger than the median firm. Clearly, this technology predicts merger patterns (or lack thereof) that are quite far from these empirical relationships. ${ }^{19}$

\footnotetext{
${ }^{19}$ Note that in an economy with no fixed cost, this technology would imply no merger activity. Merger surplus
} 
Let us now turn to the predictions of the q-theory. As discussed above, the q-theory posits that surplus is generated through merger by moving resources from less productive to more productive firms and thus that the largest joint gains are realized when the productivity differential between the two parties to a transaction is largest, i.e., $\frac{\partial\left(\sum\left(z_{a}, z_{t}\right)\right)}{\partial\left(z_{a}-z_{t}\right)}>0 .{ }^{20}$ With this assumption on the technology, we can derive the following proposition:

Proposition 2. If the merger technology embodies the q-theory, i.e., surplus is increasing in $z_{a}-z_{t}$, then (i) low $z$ targets and high $z$ acquirers will be in a greater share of matching sets and (ii) will search most intensively for partners. (iii) Low z firms will be overrepresented in the set of targets and high $z$ firms in the set of acquirers. Then (iv) the median target must be below the median firm and the median acquirer must be above the median firm, and $(v)$ the highest rate of transaction occurs between low z targets and high $z$ acquirers.

Again, the economic intuition here is straightforward. By assumption of the q-theory, for a given acquirer $z_{a}$, more surplus is generated by purchasing a lower target $z_{t}$, implying that all potential acquirers would like to purchase the least efficient target. Because expected surplus is higher for the lowest $z$ targets, it is precisely these that search for acquirers most intensively and are acquired most rapidly. Analogously, all targets would like to be purchased by the highest $z$ acquirers since the most surplus is generated, and it is this latter set of firms that search most aggressively for targets and make purchases most speedily. Because the rate of being acquired is decreasing in $z$, low $z$ firms must compose the majority of targets, driving the median target below the median firm. Similarly, because the rate of acquisition is increasing in $z$, high $z$ firms must compose the majority of acquirers. Finally, because the highest and lowest $z$ firms search the most intensively and form an acceptable match (indeed, this is the match that generates the greatest gains), they will transact with one another at the highest rate. Thus, we see that the qtheory predicts that targets should come predominantly from the smaller, less productive firms as they generate the most merger surplus and indeed, that even the highest productivity firm prefers the lowest. These predictions stand in contrast to the patterns outlined above, which revealed that target firms do not tend to come from the bottom of the firm size distribution, that the median target is the same as the median firm, and that like firms tend to match, in particular, that large predominantly buys large and only infrequently buys small.

Finally, I address a theory of purely synergistic mergers as described, for example, in RhodesKropf and Robinson (2008). The crux of this theory is that surplus is generated from the bundling

would be zero, and no firm would make an expenditure on search. For additional intuition, notice that if we posited exogenous search, that is, $\lambda$ and $\mu$ were free to the firm and exogenous, the model with this technology is analytically solvable and gives a capital gain from merger of $\frac{P c_{f}}{r+\delta+\lambda}$, that is, the gain is simply the discounted present value of the fixed cost.

${ }^{20} \mathrm{~A}$ natural example to keep in mind that is nested in (7) is $z_{m}=2 z_{a}$, which is easily derived for $\gamma=1, v=1, \alpha=$ $1, A=2$. This implies that $\tilde{z}_{m}=2 \frac{k_{a}}{k_{a}+k_{t}} \tilde{z}_{a}$, such that (1) the productivity of the merged firm $\tilde{z}_{m}$ is independent of that of the pre-merger target, and (2) when an acquirer purchases a firm with the same number of products, its physical productivity is unchanged but its $z$ doubles due to the doubling in the size of its product portfolio. If one were to interpret the q-theory as one of management discipline rather than product bundling, the results are unchanged. In the Appendix, I develop a version of the model with a homogenous product and decreasing returns in production, where mergers allow for the changing of management. As is standard, the two models give the same implications. 
of complementarity assets, that is, through assembling assets of similar quality. This is easily nested in the merger technology (7) by any set of parameters for which the technology displays both symmetry and supermodularity. ${ }^{21}$ In this case, the technology exhibits synergies from bundling in that the marginal product of each $z$ is increasing in the $z$ of the partner. I label this a theory of "pure" synergies, as complementarities imply a tendency for firms to match with like firms, and symmetry implies that from a technological point of view, the identity of the acquirer and target are irrelevant. Under these assumptions, the following proposition emerges:

Proposition 3. If the merger technology exhibits pure synergies, i.e., is symmetric and supermodular, then (i) $\Sigma\left(z_{1}, z_{2}\right)=\Sigma\left(z_{2}, z_{1}\right)$, (ii) matching sets will be symmetric around the $45^{\circ}$ line, and (iii) the mean and median difference between acquirers and targets will be zero.

Because the technology is symmetric, the same gains are generated from a match with $z_{1}$ as the acquirer and $z_{2}$ as the target as from the counterpoint match with the roles reversed. Firms' search intensities on each side of the market will be a constant multiple of the other, leading each firm to have an equal matching rate on the two sides of the market. In conjunction with the symmetric acceptance regions, this implies that every match the firm makes as the acquirer will be reflected in equal weight by the opposite match with the roles reversed. Intuitively, from a technological standpoint it is irrelevant who is the acquirer and who is the target and this indifference holds true for firms' search and acceptance decisions. It follows that in the aggregate, the mean and median differences between acquirers and targets will be zero. Again, this prediction runs counter to the data, where we see that the mean and median differences between acquirers and targets are quite large, and that the acquirer is larger than the target in about $90 \%$ of transactions.

In sum, existing theories of merger activity meet significant difficulties in matching the array of empirical merger patterns described above. With no advantages to bundling, firms merge solely for fixed cost savings. Because merger surplus is constant, all firms are willing to transact with all others, and as a result, the model predicts almost none of the matching patterns observed in the data. Under a q-theory of mergers, all firms would like to purchase the least efficient, causing these firms to compose the majority of targets. Because the most efficient firms are the most soughtafter acquirers, the highest rate of transaction occurs between the highest and lowest productivity firms. These predictions are inconsistent with the empirical finding that targets are actually not the smallest, but tend to come from the middle of the firm size distribution, and that like firms tend to transact with one another, with large only infrequently buying small. Finally, a theory of purely synergistic mergers implies that the identities of the acquirer and target are irrelevant, leading to symmetry on the two sides of the market, and in the aggregate, no differences between acquirers and targets. Again, this is inconsistent with the empirical finding that acquirers are in general larger and more profitable than their targets. I now move on the numerical analysis, where I exploit the empirical matching patterns to infer the shape of the merger technology and so how

\footnotetext{
${ }^{21}$ A natural example is $z_{m}=A\left(z_{a} z_{t}\right)^{v}$, which is obtained by setting $\gamma=0$ and $\alpha=\frac{1}{2}$, where in some abuse of notation, I have renormalized $v=\frac{1}{2} v$.
} 
surplus is generated from merger, how the gains are split, and use these results to quantitatively assess the implications of merger activity for aggregate economic outcomes.

\section{Calibration and Numerical Results}

In this section I describe the parameterization and calibration of the model and discuss the numerical results. For ease of exposition, I describe the calibration in two blocks, turning first to those parameters that are relatively standard in models of heterogeneous firms, and next to those that are new in the environment described here, where the latter are generally specific to the merger market. Table 7 lists the first set of calibrated parameter values. A time period is assumed to be one year. I normalize the mass of consumers $L$ to be 1 and the sunk cost of entry $c_{e}$ to the same. The real interest rate $r$ is set to $5 \%$. The elasticity of substitution $\sigma$ is set to 3 , which is a standard value used in the reallocation literature. ${ }^{22}$ As noted above, the exit rate generated from the model is a combination of firm shutdown through realization of the exit shock and exit through acquisition. Below, I will target the aggregate rate of acquisition, and thus I can pick $\delta$ directly to match the empirical exit rate in the US. I follow Restuccia and Rogerson (2008) and set $\delta$ so that the overall exit rate is $10 \%$, a figure that roughly coincides with the average rate of establishment exit in the US over the period 1980-2009 as reported by the Census Bureau. ${ }^{23}$ This results in a value for $\delta$ of 0.063 .

As a useful benchmark, I calibrate the entry distribution $d F(z)$ such that the endogenous distribution $d G(z)$ takes on a Pareto with shape parameter $\xi$ and where the minimum observed value will be $\hat{z}$. This is consistent with a large number of studies pointing out that the empirical firm size distribution closely approximates a Pareto. I then choose $c_{f}$ such that $\hat{z}$ is normalized to one. Following Atkeson and Burstein (2010), I set the Pareto shape parameter $\xi=1.2$, which approximates the relationship between the log of employment and the log of the fraction of total employment within firms with this level of employment or larger for the set of larger firms in the US.

Table 7: Calibrated Parameter Values (Standard Parameters)

\begin{tabular}{cllc}
\hline Parameter & Description & Target & Value \\
\hline \hline$L$ & Population & Normalization & 1 \\
$c_{e}$ & Cost of entry & Normalization & 1 \\
$r$ & Real interest rate & Real interest rate of $5 \%$ & 0.05 \\
$\delta$ & Exogenous exit rate & Overall exit rate of $10 \%$ & 0.063 \\
$\sigma$ & Elasticity of substitution & Hsieh and Klenow $(2009)$ & 3 \\
$c_{f}$ & Fixed cost of production & Normalization of $\hat{z}$ to 1 & 0.061 \\
$d F(z)$ & Entry distribution & Pareto $d G(z)$ with shape $\xi$ & 1.2 \\
\hline
\end{tabular}

\footnotetext{
${ }^{22}$ See, for example, Hsieh and Klenow (2009).

${ }^{23}$ Data obtained from http://www.census.gov/econ/susb/.
} 
We now come to the new parameters of the model, which are those governing the merger market. I parameterize the search cost functions as

$$
C_{\lambda}(\lambda)=\frac{B}{\eta} \lambda^{\eta}, C_{\mu}(\mu)=\frac{C}{\eta} \mu^{\eta}, \eta>1, B>0, C>0
$$

This gives three parameters to calibrate, those scaling the search costs $B$ and $C$ and that governing the convexity in search $\eta$, which I assume for simplicity is the same on the two sides of the market. I begin by noting that the aggregate search intensities on each side of the market are related through their ratio. For example, if $\int \lambda(z) d G(z)>\int \mu(z) d G(z)$, that is, acquirers search more intensively than targets, then, $j_{a}=\frac{\int \mu(z) d G(z)}{\int \lambda(z) d G(z)}<1$ and $j_{t}=1$. In reverse, if $\int \lambda(z) d G(z)<\int \mu(z) d G(z)$, then $j_{a}=1$ and $j_{t}<1$. The choice of cost parameters will generate aggregate search intensities on both sides of the market and give values for $j_{a}$ and $j_{t}$. Inverting this relationship, if we know the aggregate search intensity on one side of the market and the ratios $j_{a}$ and $j_{t}$, we can infer the cost parameters. This is the strategy I take.

First, I choose $B$ such that the aggregate merger rate in the model matches that observed in the data. From the combined SDC and Compustat data, I find that about 3.7\% percent of Compustat firms are acquired annually over the sample period, and I set $B$ to target this figure. This estimate is in line with evidence from Maksimovic and Phillips (2001) who report that an annual average of $3.89 \%$ of large manufacturing plants in the US changed ownership in the Longitudinal Research Database over the period 1974-1992. That the merger rate in the economy is related to the costs of search is of course quite intuitive.

Recall that $j_{a}$ and $j_{t}$ reflect the relative aggregate search intensities on the two sides of the market. To the extent that firms are searching more intensively for acquisitions or for buyers, these ratios will deviate from one. For evidence on these statistics, I examine the number of bidders per target. If the number of bidders interested in each target is significantly above one, this would serve as evidence of inequality on the two sides of the market. The SDC data, however, do not show this. Across the almost 58,000 transactions, the average number of reported bidders per target is 1.01 with only about $1 \%$ of transactions exhibiting multiple bidders. Similarly, Andrade et al. (2001) report an average of only 1.1 bidders per target over the period 1973-1998. Noting that much bidding may be non-public, Boone and Mulherin (2007) examine the sale process in detail for a sample of 400 acquisitions between 1989 and 1999. After accounting for private bids, they find a total of 1.29 bidders per target. In half of the acquisitions they investigate, the target firm only contacted a single potential buyer. In the other half, the target firm contacted an average of 21 buyers, but only received bids from an average of 1.57. Given the absence of compelling evidence that rationing plays an important role in the merger market, I choose $C$ such that aggregate search intensities are equalized, i.e., $j_{a}=j_{t}=1 .^{24}$

\footnotetext{
${ }^{24}$ Given the equilibrating forces in the model, it is not surprising that these ratios are close to 1 . Firms would be hesitant to make additional expenditures on search knowing that there is a low incremental probability of a meeting, a reasoning that would tend to result in this outcome. For a simple example, see the note following the proof of Proposition 1 in the Appendix.
} 
To set the curvature parameter $\eta$, notice that by construction, the model must match the rate of merger observed in the data. $\eta$ governs exactly how this will occur by influencing the distribution of search intensities across firms. A high value of $\eta$ implies a fast-increasing cost of search and will push the economy towards spreading out search intensities across the range of firms. A low value of $\eta$ implies the opposite, allowing for search intensities to be more concentrated within those firms with the most the most to gain from merger. In this light, we can interpret $\eta$ as regulating the dispersion in search, and I set $\eta$ to match the dispersion in the size of targets, measured by the coefficient of variation in target sales $\frac{\operatorname{std}\left(r_{t}\right)}{\operatorname{mean}\left(r_{t}\right)}$. This figure is about 3.96, reflecting the considerable heterogeneity in the size of targets.

Before turning to the merger technology, I address the Nash bargaining weight $\beta$. There is a large empirical finance literature investigating how gains from merger are shared among acquirers and targets. ${ }^{25}$ Typically, these studies examine abnormal returns in a window surrounding the merger announcement date and assess the reaction of each firm's share value. The results have been mixed, with many studies finding that the majority of gains accrue to target shareholders, and a more recent set of studies finding a more equitable split. ${ }^{26}$ Rather than relying on this literature, notice that the structural framework provides a link between the bargaining shares and merger premia. Intuitively, the merger premium reflects both the net gains from merger and the target's share. Once the gains from merger are known, equation (14) relates the merger premium directly to the target's bargaining power $1-\beta$. Hence, I set the bargaining parameter $\beta$ to match the mean merger premium of about $53 \%$.

It now remains to calibrate the merger technology governing how a merged firm is formed as the composite of the two pre-merger entities. Not surprisingly, there is a vast literature examining the gains from merger. Again, there has been a strong focus on assessing abnormal returns and the majority of studies have found positive value creation from mergers, although some have found the opposite. ${ }^{27}$ In addition to the studies of financial market reactions, a small set of papers has attempted to measure the gains from merger directly by examining the productivities of the pre- and post-merger entities. For example, Maksimovic and Phillips (2001) find that the productivity of transferred assets generally improves following an ownership change. Schoar (2002) finds similarly, but additionally that the productivity of the acquirer generally falls, resulting in a small negative effect for the acquirer. Rather than following these approaches and using financial market reactions or attempting to measure productivity effects directly, I take a different tact and calibrate the merger technology in order to match the empirical patterns of merger activity in the US. Intuitively, I am taking a revealed preference approach, relying on the idea that the patterns we observe in the data should allow us to infer how merger gains are generated.

The relationship between the shape of the surplus generating function (here, the merger technology) and the resulting matching patterns has been explored in a recent strand of search-theoretic

\footnotetext{
${ }^{25}$ See, for example, Andrade et al. (2001) and the citations therein.

${ }^{26}$ Andrade et al. (2001) find the former, and report various other studies that do the same. Ahern (2010) is a recent example finding an almost equal split.

${ }^{27}$ See Andrade et al. (2001) and the references therein.
} 
literature. A well-known finding is that to exhibit the positive sorting of the type observed in US merger activity, the technology must exhibit a certain degree of supermodularity, although the exact conditions vary with the environment. ${ }^{28}$ Most relatedly, Shimer and Smith (2000) show that with a similar CES technology in a random search environment, a necessary condition is that $\gamma \leq 0$, i.e., the elasticity of substitution be not greater than one, which corresponds to the CobbDouglas case. In light of this result, I specify the merger technology such that this assumption holds, and in particular, I use the Cobb-Douglas case of $\gamma=0$, which seems a natural starting point. We will see below that the Cobb-Douglas performs very well in replicating the empirical merger patterns. Thus, I specify

$$
z_{m}=s\left(z_{a}, z_{t}\right)=A\left(z_{a}^{\alpha} z_{t}^{1-\alpha}\right)^{v}=A z_{a}^{\gamma} z_{t}^{v}, A>0, \gamma<1, v<1
$$

where in some abuse of notation, I relabel $\alpha v$ as $\gamma$ and $(1-\alpha) v$ as $v$, and $\gamma+v$ represents the returns to scale of the technology.

The exponents $\gamma$ and $v$ jointly determine the effective productivity of the post-merger entity as a function of the two pre-merger firms. Intuitively, I assume that $\gamma<1$ and $v<1$, i.e., that each firm loses some portion of its initial productivity upon merger. The lower are $\gamma$ and $v$, the more that firms lose of their initial productivity upon merger and the less are the net gains. Knowing that its own individual quality will deteriorate more significantly upon merger induces each firm to be more selective in choosing partners, in the sense of causing matching sets to narrow. Larger values of $\gamma$ and $v$ have the opposite effect. As matching sets change, transaction rates for each firm type change as well. The change in the rate of transaction differs across firm types, however, in large part driven by the interaction with the firm size distribution. For example, consider an equivalent widening of matching sets for a high $z$ firm and a low $z$ firm. The impact on the rate of transaction will be small for the high $z$ firm, as there are few marginal firms at the borders of the matching set. For the low $z$ firm, however, many additional firms become acceptable matches, causing a disproportionate increase in transaction rates among these types. ${ }^{29}$

By regulating the size of the matching sets and the surplus generated upon merger, $\gamma$ and $v$ in large part determine the rates of search and matching among the set of firms in the market and thus the rate of transaction for each firm type. In this light, I choose $\gamma$ and $v$ to jointly match the median deviation of acquirers' and targets' size (measured in the log of sales) from the median in

\footnotetext{
${ }^{28}$ See Eeckhout and Kircher (2010) for a recent discussion.

${ }^{29}$ To gain some additional intuition here, abstract from the fixed cost savings and search market impacts of merger, and imagine a simple tradeoff between the new $z_{m}$ and the two old $z^{\prime}$ s. Consider an acquirer $z_{a}$ in a potential match with a target $z_{t}$ where $z_{t}=f z_{a}$, i.e., the target is some percentage $f$ of the size of the acquirer. To merge, it must be that $A z_{a}^{\gamma} z_{t}^{v} \geq z_{a}+z_{t}$ and rearranging gives $z_{a}^{\gamma+v-1} \geq \frac{1+f}{f^{v}} \frac{1}{A}$. For simplicity, assume $v=\frac{1}{2}$ (which is close to its calibrated value). Then for $f<1$, the RHS is strictly decreasing in $f$, meaning there is a lower bound on the size of an acceptable target. Because the LHS is increasing in $\gamma$ and the RHS is independent of $\gamma$, higher values of $\gamma$ will induce a lower threshold level of $f$. Similarly, for $f>1$, the RHS is strictly increasing in $f$, meaning there is an analogous upper bound on acceptable targets and higher values of $\gamma$ will induce a higher upper threshold level of $f$. Together, we see that higher $\gamma$ will generate a wider range of acceptable targets for a given acquirer. Similar intuition holds for changes in $v$. This simple example shows how changes in $\gamma$ and $v$ play a large role in determining matching sets and thus the transaction rates across firm types.
} 
their industries. Referring to Table 3, we see these figures are 0.58 and 0, respectively. Finally, to pin down $A$, notice that any autonomous growth from merger should have the largest effect on the merger decisions of small firms. The surplus from merger for large firms will be mostly driven by the curvature parameters, since the impact of these parameters is increasing in the size of the merger participants. On the other hand, even incremental changes in $A$ should have significant effects on the actions of smaller firms. Thus, I choose $A$ to match the percentage of targets that fall in the bottom decile of the firm size distribution, which Figure 1 shows to be $6.9 \%$.

\subsection{Computation}

Before moving on to the parameter estimates and numerical results, I outline the computational algorithm used to perform the calibration. I use a method of moments estimator with a minimum distance criterion to find the parameter values. There are seven parameters to pin down in this way, which I collect in the vector $\Theta=\{\gamma, v, A, \beta, \eta, B, C\}$. In brief, for a given candidate vector $\Theta$, I compute the equilibrium and simulate the merger market outcomes. I then construct the target moments described above from the simulated data $\Psi^{s}(\Theta)$ and compare them to the moments from the actual data $\Psi^{d}$. I iterate on the initial guess of $\Theta$ until the distance between the simulated and actual moments is minimized. Formally, the calibrated parameter vector $\Theta^{*}$ is chosen to solve

$$
\Theta^{*}=\arg \min \left(\Psi^{s}(\Theta)-\Psi^{d}\right) I\left(\Psi^{s}(\Theta)-\Psi^{d}\right)^{\prime}
$$

where $I$ is the identity matrix.

I outline the computational algorithm in Table 8. Although I believe that calibrating and computing the equilibrium in this type of economy is an important contribution of the paper, I leave the details to the Appendix. Here, I describe the general idea of my strategy and point out several notable features of the routine. In particular, the calibration is done using what I will call an "indirect" method, by which I directly construct several of the equilibrium objects in the economy and infer the parameters that lead to these outcomes. The reasoning here is that the outcomes in the calibrated economy are directly observable in the data, whereas the primitives are not, and so I can invert the mapping between primitives and outcomes to infer the former from the latter. This approach proves convenient in easing computation, particularly in light of the endogenous nature of the firm size distribution $d G(z)$ and the use of a minimization routine that necessitates solving the full equilibrium for each candidate value of the parameter vector.

The calibration follows a nested fixed point algorithm in which I guess a candidate parameter vector, solve the equilibrium under this guess, simulate data and match the simulated moments to their targets. I then iterate over the parameter vector until the objective function in (29) is minimized. Three particular features highlight the indirect nature of the algorithm: first, it proves convenient to iterate over a candidate aggregate search intensity $\mu^{c}=\int \mu(z) d G(z)$ and impose the target values of $j_{a}$ and $j_{t}$, rather than loop directly over the cost parameters $B$ and $C$. Given

values for these endogenous objects, it is straightforward to rearrange the first order conditions 
Table 8: Computational Algorithm

1. Construct $z, d G(z)$ and set direct parameters.

2. Guess candidate vector $\Theta^{c}=\left\{\gamma, v, A, \beta, \eta, \mu^{c}, j_{a}, j_{t}\right\}$.

3. Construct merger matrix $s\left(\mathbf{z}, \mathbf{z}^{\prime}\right)$.

4. Guess candidate $D=R P^{\sigma-1}$. Compute $P, \pi(z)$.

5. Guess candidate $V(z)$. Evaluate merger matrix.

6. Guess candidate $\mu(z)$ such that $\int \mu(z) d G(z)=\mu^{c}$.

7. Solve for $B, \lambda(z), C$, and new $\mu(z)$. Iterate on $\mu(z)$ until convergence

8. Solve for $c_{f}$ s.t. $V(\hat{z})=0$ and construct new $V(z)$. Iterate on $V(z)$ until convergence.

9. Construct $d F(z)$ and check free entry condition. Update $D$ until free entry satisfied.

10. Simulate data and construct target moments.

11. Compute objective function in (29) and iterate on $\Theta^{c}$ until minimized.

governing optimal search in (19) to infer the corresponding values for $B$ and $C$. Second, rather than iterate on the entry distribution $d F(z)$, I directly impose the target distribution $d G(z)$. Notice that this entails directly constructing both the density at each $z$ as well as the entry threshold $\hat{z}$. I then use the stationary conditions in (22) and the entry threshold condition (21) to infer the exogenous entry distribution $d F(z)$ and the level of the fixed $\operatorname{cost} c_{f}$ that in equilibrium give rise to the target $d G(z)$ and $\hat{z}$. Given these features, the calibration has the recursive structure outlined in Table 8 and the interested reader is referred to the Appendix for details.

\subsection{Parameter Estimates}

Table 9 lists the calibrated parameter values, as well as the empirical and simulated moments. We see that the model is capable of simultaneously replicating all seven of the target moments. Indeed, all moments are accurate to the third decimal place. In light of their importance in determining how surplus from merger is generated and split, and the longstanding literature on these topics, a brief discussion of the calibrated merger technology and bargaining shares is in order.

Table 9: Calibrated Parameter Values (Merger Market)

\begin{tabular}{cclcc}
\hline Parameter & Estimate & Target Moment & Model & Data \\
\hline \hline$\gamma$ & 0.9112 & Median deviation of $\log \left(r_{a}\right)$ & 0.577 & 0.580 \\
$\nu$ & 0.5314 & Median deviation of $\log \left(r_{t}\right)$ & 0.004 & 0.000 \\
$A$ & 1.0495 & \% of targets in lowest decile & 0.071 & 0.069 \\
$\beta$ & 0.4289 & Mean merger premium & 0.526 & 0.526 \\
$\eta$ & 13.3723 & Coefficient of variation of $r_{t}$ & 3.959 & 3.958 \\
$B$ & $3.4072 \mathrm{e}+011$ & Acquisition rate & 0.037 & 0.037 \\
$C$ & $3.2282 \mathrm{e}+012$ & Bidders per target & 1.000 & 1.000 \\
\hline
\end{tabular}

First, in line with the theory, the curvature parameters $\gamma$ and $v$ are both less than one, implying that each of the pre-transaction firms loses some of its value upon merger. However, the technology exhibits increasing returns to scale such that the proper combination of firms generates a new 
entity with higher value than the sum of the old, and merger gains are positive. That $\gamma>v$ embodies some degree of q-theory, that is, the productivity of the post-merger entity is determined to a greater extent by the productivity of the acquirer than of the target. The natural interpretation is that there is some room for the acquired assets to experience productivity gains from being incorporated into the product portfolio of the acquirer. However, if $z_{t}$ is too far below $z_{a}$, the prospect of productivity enhancement is trumped by the losses the acquiring firm will experience due to $\gamma$. The small value of $A$ implies that firms experience only a minor degree of autonomous growth from merger. While this has small influence on the decisions of large firms, it gives impetus for the amount of merger activity among small firms observed in the data, in addition to the prospect of fixed cost savings. Thus, the merger technology exhibits incentives for both positive sorting due to synergies, through the complementarity of the technology, and for productivity improvements through the asymmetry in $\gamma$ and $v$.

Next, the value of $\beta$ implies that the gains from merger are split with reasonable equality, with about $57 \%$ of gains going to targets and $43 \%$ to acquirers. As discussed above, the corporate finance literature has long pointed out that financial market returns imply that the lion's share of gains go to targets, where a more recent set of studies find a more equitable split. My results are in line with this latter finding. Recall that my estimate relies on interpreting the merger premium as reflecting a combination of target bargaining power and the size of the merger surplus. Given the surplus patterns predicted by the model, bargaining shares must be relatively balanced to imply premia on the order of magnitude observed in the data.

I believe these parameter estimates to hold some independent interest, as they shed new light on exactly how surplus from merger is generated and split. I depart from existing studies by relying on the empirical ex-ante matching patterns to infer how merger gains are generated from various combinations of firms, and how they are shared among the transacting parties. Forming a deeper understanding of the microstructure that would generate a merger technology of the form estimated here, and investigating the process that would imply this split of surplus and why it may not be reflected in financial market performance, are clearly interesting avenues to pursue.

\subsection{Non-Targeted Moments}

Table 9 shows that the model is capable of matching the set of targeted moments quite closely. Here, I document how the model performs on some other moments of interest. First, notice that I do not target any moment directly regulating the degree of assortative matching between acquirers and targets. Although the Cobb-Douglas assumption implies some amount of positive sorting, the degree to which firms are willing to match below or above their own type is also to a great extent influenced by the calibrated parameters of the merger technology. In Table 10, I compare the $\log$ correlations of acquirer and target sales, employment, and market value from the model and the data. We see that the model predicts an amount of sorting very close to what is observed in the data. Additionally, I show the fraction of transactions in which the size of the acquirer exceeds that of the target from the model compared to the data, where the former is measured by $z$ and the 
latter is an average over the size metrics in Table 2. The model performs quite well in predicting the share of transactions in which the acquirer is larger and more profitable than the target.

Table 10: Predicted Matching Moments

\begin{tabular}{lcc}
\hline Moment & Model & Data \\
\hline \hline Corr $\left(\log r_{a}, \log r_{t}\right)$ & 0.58 & 0.62 \\
Corr $\left(\log l_{a}, \log l_{t}\right)$ & 0.58 & 0.58 \\
Corr $\left(\log V_{a}, \log V_{t}\right)$ & 0.71 & 0.64 \\
Share of transactions with $z_{a}>z_{t}$ & 0.86 & 0.90 \\
\hline
\end{tabular}

Next, I assess the ability of the model to replicate the characteristics of the set of transacting firms. In particular, Figure 1 revealed that the share of acquirers in each decile of the firm size distribution is monotonically increasing, with acquirers overrepresented in the top deciles and underrepresented at the bottom. In contrast, targets are generally drawn from the middle deciles, and underrepresented at both extremes. In Figure 5, I compare the distributions of acquirers and targets across the deciles of the firm size distribution from the model and the data. The top row replicates Figure 1 in showing the distributions from the data and the bottom row shows the distributions as computed from the model simulation. The model replicates quite closely the empirical distributions. For acquirers, the model generates the monotonic pattern observed in the data, with acquirers overrepresented in the top 5 deciles and underrepresented in the bottom 5. The model somewhat underpredicts the share of acquirers at the bottom and overpredicts the share of acquirers at the top. This is likely due to an overestimation of merger surplus among the largest firms through the convexity of the merger technology. Turning to targets, we see that the model matches almost exactly the data. Recall that I target the share of targets in the lowest decile (the bar on the far left) to pin down $A$, but not the remainder of the distribution. The model predicts that targets are underrepresented at the extreme deciles ( 2 on either side), and tend to be drawn from the middle of the firm size distribution, exactly the pattern across deciles observed in the data.

\subsection{Policy Functions}

I now turn to firm actions on the merger market. In Figure 6, I show the firm policy functions, that is, optimal search intensities and acceptance regions. Panel A shows that search intensities are increasing in $z$ on both sides of the market, an intuitive result given the convexity of the merger technology. The expected surplus from a consummated merger is increasing in firm size for both targets and acquirers. Despite the fact that large firms search most intensively, the shape of the firm size distribution limits the number of transactions between the largest firms that take place. It is difficult for two large firms to meet simply due to the Pareto distribution, which implies that there are not many large firms in the economy. The figure also reveals that smaller firms tend to search more intensively for potential buyers and large firms for potential targets. Intuitively, for 

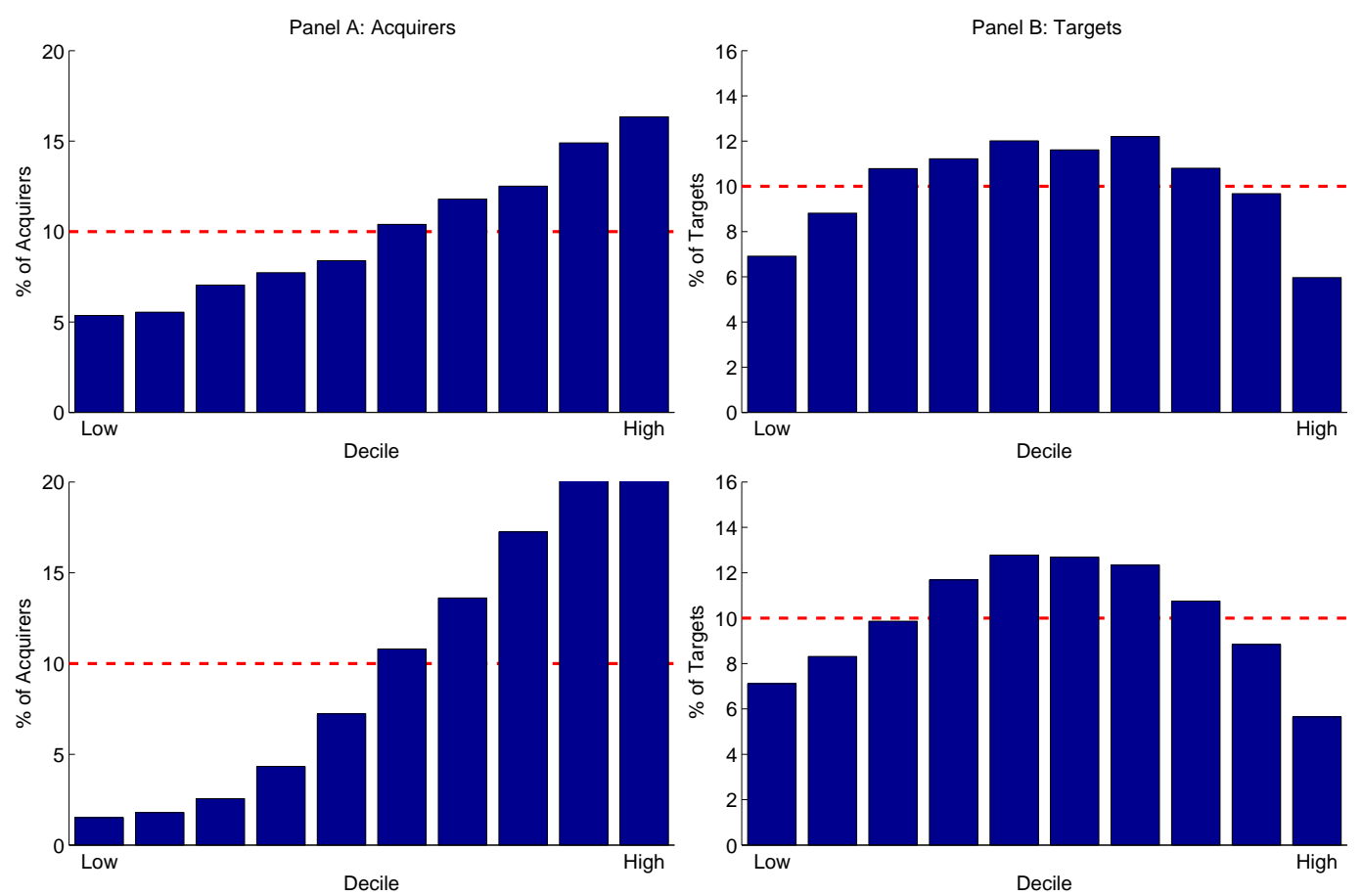

Figure 5: Decile Shares of Transacting Firms: Data (top) vs Model (bottom)

lower $z$ firms, the expected surplus from being acquired is higher than from acquiring another firm. Together, we see how the search intensities of individual firms aggregate to form the pattern of transacting firms seen, for example, in Figure 5.

Panel B displays the acceptance regions for completing a transaction. Shimer and Smith (2000) show that under certain assumptions on the merger technology, and in particular on the degree of supermodularity, it can be proved that matching sets are convex, closed, and nonempty, implying that they can be characterized by lower and upper bound functions. That is, there exists a minimum and maximum target with which a given acquirer is willing to transact, and that acquirer is also willing to transact with any target falling in between. A symmetric result is true for targets. I make use of this finding here and simply display the bound functions. Any meeting between an acquirer and target falling inside the two bounds is then an acceptable match. Reading across the x-axis, a candidate target $z_{t}$ is willing to sell itself to any acquirer along the vertical distance between the two bounds functions. Similarly, reading up the y-axis, a candidate acquirer $z_{a}$ is willing to purchase any target along the horizontal distance between the two bounds.

Referring to the empirical scatterplot of matches in Figure 2, we gain some intuition for how the model predicts the observed merger patterns. The data show that firms of a given size tend to have a range of firms with which they are willing to match. The model with search and matching frictions is able to replicate this pattern. Indeed, that search frictions will generate a range of acceptable matches for each type is a central feature of Shimer and Smith (2000). The data also reveal that the range of acceptable matches is increasing in firm size, i.e., the acceptable size range for one's partner is increasing in one's own size. This pattern is replicated by the model, which 

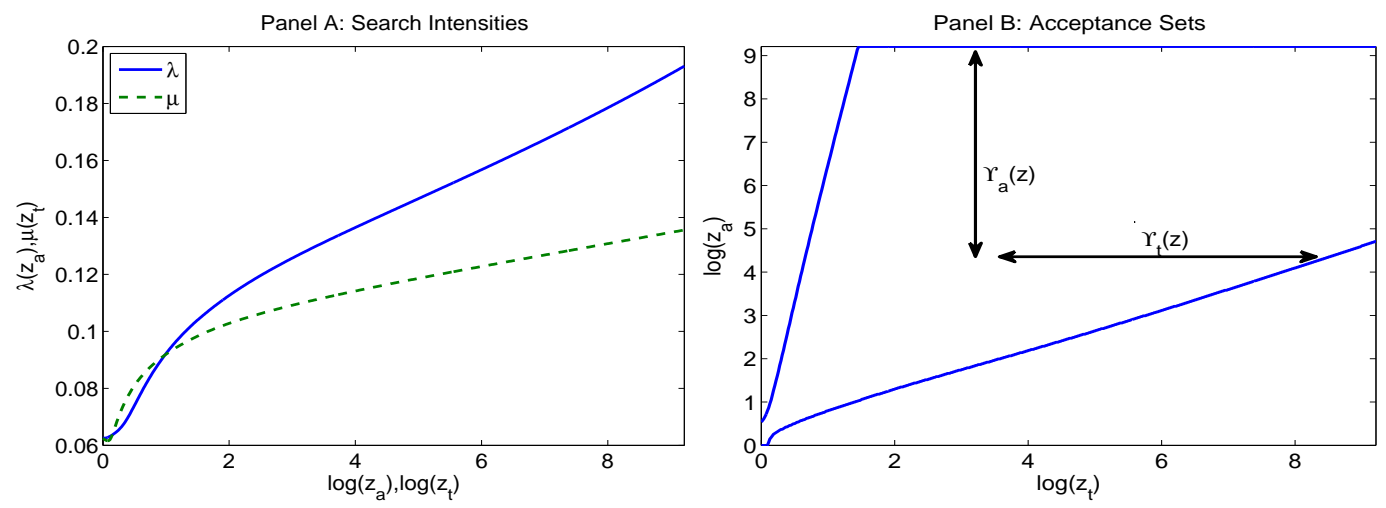

Figure 6: Merger Market Policy Functions

generates bound functions that are increasing in $z$, that is, higher $z$ firms are willing to match with higher $z$ firms on the other side of the market. This result is in line with Shimer and Smith (2000), who prove that it will hold with the proper degree of supermodularity on the surplus technology. Figure 6 reveals how firm decisions in the calibrated economy aggregate to replicate the empirical matching sets, which then interact with the firm size distribution to generate search intensities and matching rates consistent with those observed in the data.

\section{The Aggregate Impact of Mergers and Acquisitions}

To evaluate the aggregate impact of mergers and acquisitions, I solve for the stationary equilibrium in an economy with no M\&A, calculate the economic aggregates, and compare them to those generated in the economy with M\&A. We can interpret the no-M\&A economy as one where government policies are extremely restrictive in preventing all merger transactions, or where the costs of search are prohibitively high. In the absence of M\&A, the economy is essentially the closed-economy version of Melitz (2003). As a world investigated thoroughly in the literature, this would seem a natural benchmark to use in exploring the influence of M\&A. After calculating the outcomes in the no-M\&A economy, I assess the contribution of M\&A to aggregate economic performance. The gains I calculate are from comparisons of two stationary equilibria and so focus only on the long-run effects of M\&A.

I present the results in Table 11. The table shows the value of each statistic in the stationary equilibrium of the economy with $\mathrm{M} \& \mathrm{~A}$ as a percentage of its value in that of the no-M\&A economy. Immediately, we see that M\&A activity has a significant beneficial impact on aggregate economic performance. Aggregate productivity and output are both 31\% higher and the aggregate price level 33\% lower with M\&A than without. Recall that (26) implies that changes in these metrics should be proportional to one another. There is a large increase in the productivity index $\bar{Z}$, inducing much of the change in these outcomes. Additionally, and perhaps surprisingly, the mass of firms is actually somewhat higher with M\&A than without. Despite the fact that firms are exiting at faster rate by being acquired, in general equilibrium, the existence of the merger market 
actually entices additional firms to enter, more than offsetting the reduction caused by acquisition. Intuitively, the value stemming from potential participation in the merger market induces entry by entrepreneurs that may otherwise not have done so. Note that the increase in the mass of firms does not imply that concentration is reduced by M\&A. In fact, the model follows standard intuition and predicts the opposite, that M\&A will increase industry concentration. While more firms are entering and producing, a greater share of resources is being transferred to the largest firms, and they are reaping an even greater share of industry sales. ${ }^{30}$

Table 11: The Aggregate Impact of M\&A

\begin{tabular}{lc}
\hline Statistic & \% of value with no M\&A \\
\hline \hline Aggregate Productivity & 131.0 \\
Output & 131.0 \\
Aggregate Price & 76.3 \\
Mass of firms & 110.4 \\
Consumption & 113.4 \\
Welfare & 110.7 \\
\hline
\end{tabular}

Using (26), it is straightforward to decompose the gains from M\&A into those stemming from a greater number of firms, and those from a higher productivity index $\bar{Z}$. Doing so reveals that about $18 \%$ of the gains are due to the former, and $82 \%$ to the latter. The reallocative effects of M\&A thus account for the lion's share of the aggregate performance gains. To highlight this result, I display in Panel A of Figure 7 the initial entry distribution and the endogenous distributions over operating firms in the economies with M\&A and without (I truncate the values of $z$ in order to focus on the differences in the distributions). Clearly, the endogenous distributions in both worlds dominate the entry distribution, and that in the economy with M\&A dominates that in the economy without. This is a result both of reallocation on the intensive margin, i.e., among firms that choose to operate in both economies, and the extensive margin, i.e., of redistributing mass from firms that fall below the entry threshold in the economy with M\&A to those that fall above. In Panel B, I display the pure redistributional effects of M\&A, abstracting from the extensive margin. Specifically, I show the type distribution in the economy with M\&A and that in the economy without, conditional on falling above the entry threshold with M\&A. The distribution with M\&A dominates that without M\&A over the majority of the long right tail, implying a greater mass for high productivity firms. The crossing of the distributions illustrates how this results from the flow of resources from lower to higher productivity firms. The figure clearly shows how redistribution occurs along both the extensive and intensive margins, and jointly, the aggregate reallocative effects of $\mathrm{M} \& \mathrm{~A}$ in transferring resources to the most productive firms.

In line with the positive effects of M\&A on industrial performance, consumers benefit to a great extent as well. Consumption is 13\% larger with M\&A and welfare almost 11\% higher. Although

\footnotetext{
${ }^{30}$ For example, using the Gini coefficient to measure concentration shows an increase from 0.58 to 0.67 when moving to the economy with M\&A, signaling a greater degree of inequality.
} 

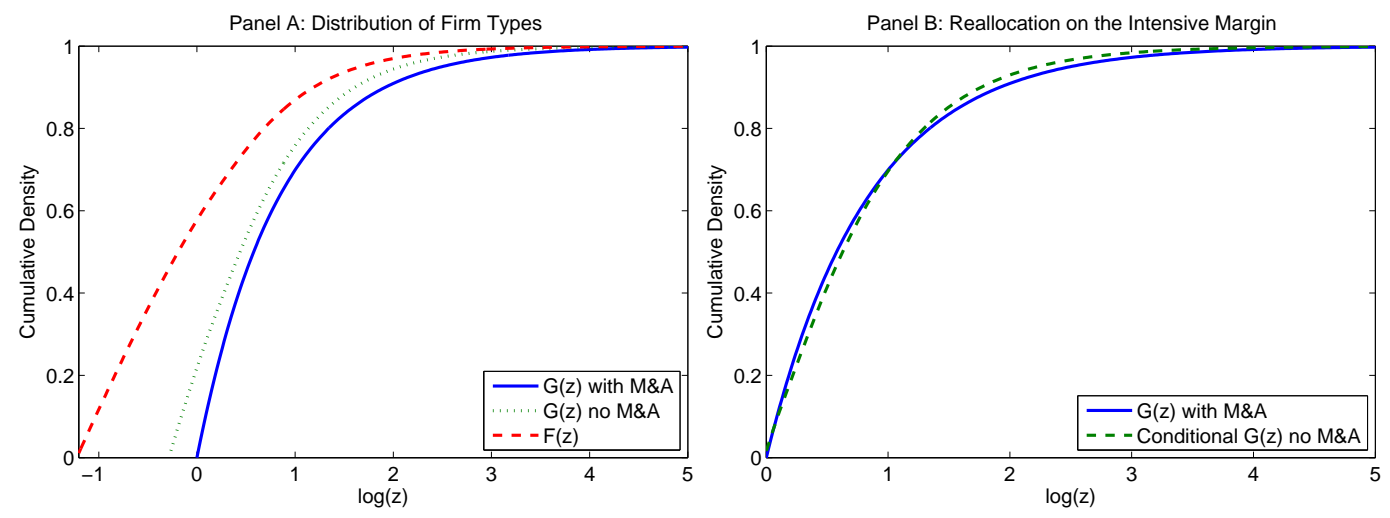

Figure 7: The Redistributive Effects of M\&A

still considerable, the gains in consumption are quite a bit smaller than those in productivity and output. The reason is that M\&A changes the allocation of final output across its various uses. In particular, more of final output must be devoted to the fixed costs of production, the costs of searching on the merger market, and the costs of firm creation. In the economy with no M\&A, $22 \%$ of output goes towards these uses, a figure that jumps to $33 \%$ with M\&A. Interestingly, the main culprit is not expenditures on search in the merger market, which represent only about $1 \%$ of final output. Rather, there is a large rise in the amount of resources going towards the creation of new firms.

The increase in new firm creation is attributable to several effects. Recall that the total resource costs of new entry are $M_{e} c_{e}$ and using (23), the mass of entrants is given by

$$
M_{e}=\frac{\left\{\delta+\int \mu(z) j_{t}\left[\int \Phi\left(\Sigma\left(z_{a}, z\right)\right) \Lambda\left(z_{a}\right) d G\left(z_{a}\right)\right] d G(z)\right\} M}{1-F(\hat{z})}
$$

i.e., must equal the aggregate rate of exit multiplied by the mass of incumbent firms divided by the probability of successful entry upon drawing a $z$. In order to sustain the stationary equilibrium, the increase in the aggregate exit rate caused by the acquisition of targets necessitates a corresponding increase in the mass of entrants. Second, we have already seen that the merger market induces a higher mass of incumbent firms due to the additional value stream stemming from the potential for merger, also requiring a greater number of entrants. Lastly, increased selection on the extensive margin due to M\&A causes a reduction in the probability of successful entry, implying that more potential entrants must make a productivity draw in order to garner the required number of successful entrants. All of these effects work to increase the mass of potential entrants, each of which must pay the sunk cost of entry. Thus, a larger share of resources is devoted to paying the resource costs of new firm creation for both successful and unsuccessful entrants in the economy with M\&A than in that without, and this accounts for the majority of the difference in the movements of output and consumption. However, we see that the reallocation of resources away from final consumption is more than offset by the rise in output, leading to net gains in consumption 
and welfare.

The results suggest that M\&A has a great potential for improving long-run economic performance. To check the sensitivity of these findings, I analyze the elasticities of aggregate productivity and consumption with respect to the merger market parameters in Table 9, which are those new to the environment outlined above. The elasticities are generally quite small, and hence I do not report the results here. ${ }^{31}$ As a last remark, the benchmark economy considered here is extreme in the sense of a complete absence of M\&A. Investigating the influence of empirically relevant intermediate policies would prove fruitful for subsequent work, particularly those related to firm size. The effects of policy in this environment are complex and can be either beneficial or detrimental, depending crucially on the particular nature of the policy under consideration and its impact on the decisions of firms across the type spectrum. Additionally, the stylized nature of the model abstracts from endogenous firm growth through channels alternative to M\&A and a corresponding choice of de novo investment. Whether the inclusion of this feature would increase or mitigate the gains to M\&A found here is unclear, depending on which firms choose which avenue for growth and the associated costs to society.

\section{Conclusion}

This paper develops a search-theoretic model of mergers and acquisitions in a dynamic general equilibrium setting and assess the implications for aggregate economic performance. I use a transaction-level dataset to document a number of empirical patterns in US merger activity and build a parsimonious framework that is able to address these facts and nests several existing theories of merger activity as special cases. I explore the merger patterns predicted by these theories and show that each meets difficulties in fitting the full set of empirical facts. I calibrate the model to match moments from the transaction-level data, as well as other salient features of the US economy. The calibrated model is capable of replicating the stylized facts quite closely and sheds new light as to how surplus is generated from merger and how the gains are split. I find that merger activity generates potentially large long-run gains in aggregate performance, measuring about 30\% in aggregate productivity and output, and about $11 \%$ in welfare.

In assessing the implications of mergers and acquisitions in a fully articulated dynamic general equilibrium framework, this paper takes a somewhat different approach from the existing literature, a departure that I believe is rewarded by the new insights the model provides into the causes and consequences of M\&A activity. An important area for further exploration is in providing explicit microfoundations for the merger technology. Although I successfully discipline the shape of the merger technology in the sense of closely matching the empirical patterns of M\&A, I do not model the underlying mechanism through which firms aggregate products and/or managers

\footnotetext{
${ }^{31} \mathrm{~A}$ caveat here is that a small positive shock to $\gamma$ has a fairly significant effect on aggregate productivity (on the order of plus $4 \%$ ), although this is largely washed out when moving to consumption, and an equal-sized negative shock induces a response only half that size. The convergence properties of the model become problematic as $\gamma$ nears 1 , likely because the model is approaching an explosive solution, rendering this type of shock unreliable.
} 
that generates a technology of this form. A better understanding of this process would make clear exactly how the roles of complementarities and productivity enhancements combine to determine the observed merger technology and so the patterns of matching observed in the data.

While the model highlights the long run benefits associated with M\&A activity, the literature has long been interested in its higher frequency behavior in the form of merger waves and cyclical properties. Examples of the former include Jovanovic and Rousseau (2008) and Harford (2005) and of the latter, Eisfeldt and Rampini (2006). Search environments of the form here have rich dynamic implications, as shown for example, by Lu and McAfee (1996) and Shimer and Smith (2001b). Taking the model out of stationary equilibrium and analyzing its short-run dynamic behavior holds some promise in generating new insights into merger waves and the cyclical behavior of merger activity.

Finally, the model abstracts from strategic interactions in merger activity. Gowrisankaran (1999) develops and simulates a dynamic empirical model of mergers with this feature, revealing the assumptions and limitations necessary to maintain tractability in such a framework. Extensions of the model in this direction would clearly be of great interest. The absence of strategic motives does not, however, preclude a role for policy in the current model. As pointed out in Shimer and Smith (2001a), search and matching behavior is generally inefficient in this environment due to standard search externalities. The nature of these externalities in the present context, where repeat matching is feasible and agents' values are heterogeneous and determined in general equilibrium is not obvious, and nor is the set of policies that may replicate the social optimum. Interestingly, Shimer and Smith (2001b) show that optimal policy in this type of environment may be nonstationary, with the implication for the model here being that merger waves may reflect, at least in part, the optimal matching path.

\section{References}

AHERN, K. (2010): "Bargaining Power and Industry Dependence in Mergers," Journal of Financial Economics, forthcoming.

Andrade, G., M. Mitchell, And E. Stafford (2001): “New Evidence And Perspectives on Mergers," Journal of Economic Perspectives, 15, 103-120.

AtKeson, A. AND A. Burstein (2010): “Innovation, Firm Dynamics, and International Trade," The Journal of Political Economy, 118, 433-484.

Boone, A. And J. Mulherin (2007): “How Are Firms Sold?” The Journal of Finance, 62, 847-875.

DePAmphilis, D. (2009): Mergers, Acquisitions, and Other Restructuring Activities: An Integrated Approach to Process, Tools, Cases, and Solutions, London, U.K.: Academic Press.

EeckHout, J. AND P. KirCheR (2010): “Sorting and Decentralized Price Competition," Econometrica, 78, 539-574. 
EISFELDT, A. AND A. RAMPINI (2006): “Capital Reallocation and Liquidity," Journal of Monetary Economics, 53, 369-399.

- (2008): "Managerial Incentives, Capital Reallocation, and the Business Cycle," Journal of Financial Economics, 87, 177-199.

GOWRISANKARAN, G. (1999): “A Dynamic Model of Endogenous Horizontal Mergers," The RAND Journal of Economics, 30, 56-83.

HARford, J. (2005): “What Drives Merger Waves?” Journal of Financial Economics, 77, 529-560.

Hopenhayn, H. (1992): “Entry, Exit, and Firm Dynamics in Long Run Equilibrium," Econometrica, 60, 1127-1150.

HsieH, C. AND P. KLENOW (2009): “Misallocation and Manufacturing TFP in China and India," The Quarterly Journal of Economics, 124, 1403-1448.

Jovanovic, B. And P. Rousseau (2002): “The Q-Theory of Mergers," American Economic Review, 92, 198-204.

(2008): “Mergers as Reallocation," The Review of Economics and Statistics, 90, 765-776.

LAGOS, R. (2006): “A Model of TFP,” Review of Economic Studies, 73, 983-1007.

LU, X. AND R. McAfEe (1996): "Matching and Expectations in a Market with Heterogeneous Agents," Advances in Applied Microeconomics, 6, 121-156.

LUCAS JR, R. (1978): “On the Size Distribution of Business Firms," The Bell Journal of Economics, 9, 508-523.

MAKsimovic, V. AND G. PHILliPS (2001): “The Market for Corporate Assets: Who Engages in Mergers and Asset Sales and Are There Efficiency Gains?" The Journal of Finance, 56, 2019-2065.

MARTOS-VILA, M. (2008): “The Search for Corporate Control,” mimeo, UCLA.

Melitz, M. (2003): “The Impact Of Trade On Intra-Industry Reallocations and Aggregate Industry Productivity," Econometrica, 71, 1695-1725.

Restuccia, D. And R. Rogerson (2008): "Policy Distortions and Aggregate Productivity with Heterogeneous Establishments," Review of Economic Dynamics, 11, 707-720.

Rhodes-KRopf, M. AND D. Robinson (2008): “The Market for Mergers and the Boundaries of the Firm," The Journal of Finance, 63, 1169-1211.

SCHOAR, A. (2002): "Effects of Corporate Diversification on Productivity," Journal of Finance, 57, 2379-2403.

SHIMER, R. AND L. SMith (2000): “Assortative Matching and Search," Econometrica, 68, 343-369. 
- (2001a): "Matching, Search, and Heterogeneity," The BE Journal of Macroeconomics, 1, 5.

_ (2001b): “Nonstationary Search," mimeo, University of Chicago and University of Michigan.

Whinston, M. (2007): “Antitrust Policy toward Horizontal Mergers," Handbook of Industrial Organization, 3, 2369-2440.

\section{A Data}

In this Appendix, I describe in more detail the data used in the paper, beginning with SDC. As described in the text, I select from SDC all domestic transactions announced between 1977 and 2009 with a nominal deal value of at least $\$ 1$ million. I include only completed transactions, those not classified as hostile (only about 300 transactions are classified as hostile takeovers), those in which the acquirer newly gains majority control of the target, and those with relevant ownership status. After this process, and eliminating several observations with obvious data entry errors, there are 57,858 transactions. For each transaction, I obtain the following data (when available): transaction value (total value of consideration paid by the acquirer, excluding fees and expenses), premium (premium of offer price to target closing stock price 4 weeks prior to the original announcement date), and standard performance variables including net sales, employment, PP\&E, EBITDA, and market value.

As mentioned in the text, data availability differs across the SDC variables. In Table 12, I show the number of transactions with available data for acquirers, targets, and both, for each dimension of analysis.

Table 12: SDC Data Availability

\begin{tabular}{lccc}
\hline & Acquirer & Target & Both \\
\hline \hline Sales & 31,736 & 18,541 & 12,251 \\
Employment & 28,050 & 6,138 & 3,957 \\
PP\&E & 28,792 & 10,095 & 6,672 \\
EBITDA & 26,424 & 8,208 & 5,080 \\
Market Value & 25,38 & 6,969 & 4,112 \\
Premium & $*$ & $*$ & 6,474 \\
\hline
\end{tabular}

Moving to Compustat, I obtain data on the universe of firms contained in the CRSP/Compustat merged database (CCM) from 1977 to 2009. This yields a total of 210,275 observations. The SDC to Compustat match is not straightforward since the two databases use different company identifiers. The most specific identifier provided by SDC is the 6-digit CUSIP for both parties in each transaction. This is not sufficient for the match, however, because Compustat only records the most recent CUSIP rather than a CUSIP history. Because of this, matching on CUSIP may result in missed pairs and erroneous matches. 
To perform the match, I use the CRSP translator to associate 6-digit CUSIPs from SDC with the CRSP company identifier. I then match this identifier with the CCM database, which already associates the CRSP identifier with the set of Compustat firms. I follow this process for both acquirers and targets. I associate transactions with the Compustat data for the fiscal year preceding the year of merger announcement. I obtain data on net sales, employees, PP\&E (net of depreciation), EBITDA, and market value, where I calculate the latter as the product of common shares outstanding and the closing price at fiscal year end. Table 13 shows availability of the Compustat data:

Table 13: Compustat Data Availability

\begin{tabular}{lcccc}
\hline & All Firms & Acquirers & Targets & Both \\
\hline \hline Sales & 191,992 & 30,453 & 6,828 & 4,465 \\
Employment & 179,787 & 28,597 & 6,186 & 3,862 \\
PP\&E & 187,270 & 28,368 & 6,608 & 4,284 \\
EBITDA & 152,671 & 25,472 & 5,525 & 3,478 \\
Market Value & 206,309 & 30,890 & 6,913 & 4,548 \\
\hline
\end{tabular}

Macroeconomic data are obtained from standard sources. US GDP and stock of fixed assets are from the Bureau of Economic Analysis (http://www.bea.gov/). The CPI is from the Bureau of Labor Statistics (http:/ /www.bls.gov/).

\section{B Span of Control}

There is a well-known isomorphism between economies with differentiated varieties, monopolistic competition, and constant marginal costs, and those with a homogenous good, perfect competition, and diminishing returns (increasing marginal costs) in production, as in the Lucas Jr (1978) span of control model. This translation holds in the present context as well. Here, I outline this latter version of the model.

There is a single homogenous good produced using labor. The production function exhibits diminishing returns and takes the form $q=z^{1-\theta} l^{\theta}$ where the normalization of $z$ plays a similar role as in the text of the paper. Competitive firms take the market price $P$ as given and choose labor to maximize profits, $P z^{1-\theta} l^{\theta}-l$ where I have normalized the wage $w=1$ to be numeraire. Standard arguments give labor demand, revenue, and variable profits from sales as

$$
\begin{aligned}
l & =(\theta p)^{\frac{1}{1-\theta}} z \\
r & =P^{\frac{1}{1-\theta}} \theta^{\frac{\theta}{1-\theta}} z \\
\pi & =(1-\theta) P^{\frac{1}{1-\theta}} \theta^{\frac{\theta}{1-\theta}} z
\end{aligned}
$$

and so as above, firm product market outcomes are proportional to $z$ and depend on industry aggregates that are common across all firms, here the span of control parameter $\theta$ and the compet- 
itive price of output $P$.

The merger market works analogously to the manner described above, where mergers allow firms to improve their productivity $z$. The merger technology combines the $z$ 's of an acquirer and target and produces a firm with a new $z$. Because there is only a single homogenous good, the firm's $z$ represents only its physical productivity, rather than the product of its productivity and number of products as in the differentiated goods model in the paper. The merger technology is then interpreted as directly combining productivities, with no role for the size of the firm's product suite. The interpretation here is one of management discipline, where mergers allow for productivity improvement through the incorporation of new management. All the dynamic equations of the model are the same.

\section{Proofs}

Proposition 1. Conjecture that the gains from merger are constant and strictly positive across all firm types, i.e., $\Sigma\left(z_{a}, z_{t}\right)=\bar{\Sigma}>0 \forall z_{a}, z_{t}$. Then, all meetings will result in a completed transaction and we can write the value function as

$$
(r+\delta) V(z)=\pi(z)-P C_{\lambda}(\lambda(z))-P C_{\mu}(\mu(z))+\lambda(z) j_{a} \beta \bar{\Sigma}+\mu(z) j_{t}(1-\beta) \bar{\Sigma}
$$

The first order conditions governing optimal search in (19) give

$$
\begin{aligned}
P C_{\lambda}^{\prime}(\lambda(z)) & =j_{a} \beta \bar{\Sigma} \\
P C_{\mu}^{\prime}(\mu(z)) & =j_{t}(1-\beta) \bar{\Sigma}
\end{aligned}
$$

which shows that the choice of $\lambda$ and $\mu$ are constant and independent of $z$. Denoting these common search intensities as $\bar{\lambda}$ and $\bar{\mu}$, we can rewrite the value function as

$$
(r+\delta) V(z)=\pi(z)-P C_{\lambda}(\bar{\lambda})-P C_{\mu}(\bar{\mu})+\bar{\lambda} j_{a} \beta \bar{\Sigma}+\bar{\mu} j_{t}(1-\beta) \bar{\Sigma}
$$

The surplus from a merger between a type $z_{a}$ acquirer and type $z_{t}$ target is $\Sigma\left(z_{a}, z_{t}\right)=V\left(z_{m}\right)-$ $V\left(z_{a}\right)-V\left(z_{t}\right)$. Using (30), it is straightforward to show that surplus equals

$$
\frac{\pi\left(z_{m}\right)-\pi\left(z_{a}\right)-\pi\left(z_{t}\right)-\bar{\lambda} j_{a} \beta \bar{\Sigma}-\bar{\mu} j_{t}(1-\beta) \bar{\Sigma}+P C_{\lambda}(\bar{\lambda})+P C_{\mu}(\bar{\mu})}{r+\delta}
$$

Under the assumption that the merger technology displays no gains from bundling, we have

$$
\pi\left(z_{m}\right)-\pi\left(z_{a}\right)-\pi\left(z_{t}\right)=P c_{f}
$$


that is, the only gain in flow profits from merging is a single fixed cost savings. Then,

$$
\Sigma\left(z_{a}, z_{t}\right)=\frac{P c_{f}-\bar{\lambda} j_{a} \beta \bar{\Sigma}-\bar{\mu} j_{t}(1-\beta) \bar{\Sigma}+P C_{\lambda}(\bar{\lambda})+P C_{\mu}(\bar{\mu})}{r+\delta}=\bar{\Sigma}>0
$$

Thus, we have proved our initial conjecture that the gains from merger are constant and independent of $z$ and (i) that every meeting will result in merger.

Because each firm searches with the same intensities, and the effective meeting rates on the two sides of the market must equate, each firm has an equal probability of meeting a particular partner as an acquirer or a target. That is, the rate at which acquirer $z_{1}$ meets target $z_{2}$ equals the rate at which acquirer $z_{2}$ meets target $z_{1}$. That meetings are random and all result in a completed transaction, that all firms choose the same search intensities, and that each transaction is reflected by the opposite transaction with the roles reversed in equal weight together imply that (ii) the correlation between the characteristics of targets and acquirers is zero, (iii) the mean and median difference between targets and acquirers are zero, and (iv) the median target and median acquirer are the same as the median firm.

Before moving on to proposition 2, a few additional notes are in order. In particular, let us gain some intuition by parameterizing the search cost functions as in (27), and assuming, for example, that $\int \lambda(z) d G(z)>\int \mu(z) d G(z)$. In this case, we can derive

$$
\begin{aligned}
& \bar{\lambda}=\left[\left(\frac{1-\beta}{C}\right)^{\frac{1}{\eta}}\left(\frac{\beta}{B}\right)^{\frac{\eta-1}{\eta}} \frac{\bar{\Sigma}}{P}\right]^{\frac{1}{\eta-1}} \\
& \bar{\mu}=\left[\frac{1-\beta}{P C} \bar{\Sigma}\right]^{\frac{1}{\eta-1}} \\
& j_{a}=\left[\frac{1-\beta}{\beta} \frac{B}{C}\right]^{\frac{1}{\eta}}
\end{aligned}
$$

that is, the ratio of search on the target and acquirer sides of the market is independent of the merger surplus and depends only on the ratio of bargaining shares and real search costs on each side. Because targets are on the short side of the market, their search intensity only depends on their expected surplus and costs of search. Because acquirers are on the long side of the market, their search intensity is increasing in their expected surplus, decreasing in their costs of search, but is increasing (although at a slower rate) in the expected surplus and decreasing in the costs of search for targets. This is because as these latter increase, targets will search more intensively, which increases the effective meeting rate for acquirers. From here, we can solve for the merger surplus up to a single nonlinear equation in $\bar{\Sigma}$ :

$$
\frac{\eta-1}{\eta}\left(\frac{1-\beta}{P C}\right)^{\frac{1}{\eta-1}} \bar{\Sigma}^{\frac{\eta}{\eta-1}}+(r+\delta) \bar{\Sigma}-P c_{f}=0
$$


If we had alternatively assumed that $\int \lambda(z) d G(z)<\int \mu(z) d G(z)$, we would have obtained analogous expressions. Notice that if $c_{f}=0$, there is no solution such that $\bar{\Sigma}>0$ and there will be no mergers. If the merger technology displays no gains from bundling and there is no fixed cost of production, there are no gains to merging, and no firms will expend any resources to do so.

Proposition 2. Assume that merger surplus $\Sigma\left(z_{a}, z_{t}\right)$ is increasing in the distance between the acquirer and target $z_{a}-z_{t}$. Then for a given $z_{a}$, surplus is decreasing in $z_{t}$, and so the set of acceptable targets $Y_{t}\left(z_{a}\right)$ is characterized by an upper threshold $z_{t}^{*}$ such that $\Sigma\left(z_{a}, z_{t}^{*}\right)=0$. That is, acquirer $z_{a}$ will be willing to purchase any targets with $z \leq z_{t}^{*}$. It is straightforward to establish an analogous result for targets, that is, $\mathrm{Y}_{a}\left(z_{t}\right)$ is characterized by a lower threshold $z_{a}^{*}$ such that target $z_{t}$ will sell itself to any acquirer with $z \geq z_{a}^{*}$. Together these imply (i) low $z$ targets and high $z$ acquirers are in a greater share of matching sets. That surplus is decreasing in $z_{t}$ and increasing in $z_{a}$ implies that expected surplus conditional on meeting a candidate purchaser or target, defined in (17), are also respectively decreasing and increasing in $z$. From the first order conditions governing optimal search (19), we see that search intensities $\mu(z)$ and $\lambda(z)$ must be decreasing and increasing in $z$ respectively, that is, (ii) low $z$ targets and high $z$ acquirers search most intensively for partners. The fact that low $z$ targets and high $z$ acquirers are in a greater share of matching sets and search most intensively together imply that the rate at which firms are acquired $\mu(z) j_{t} \int \Phi\left(\Sigma\left(z_{a}, z\right)\right) \Lambda\left(z_{a}\right) d G\left(z_{a}\right)$ is decreasing in $z$ and similarly the rate at which they make acquisitions $\lambda(z) j_{a} \int \Phi\left(\Sigma\left(z, z_{t}\right)\right) \Gamma\left(z_{t}\right) d G\left(z_{t}\right)$ is increasing in $z$. It is then immediate that (iii) low $z$ firms are overrepresented in the set of targets and high $z$ firms in the set of acquirers and that (iv) the median target is below the median firm and the median acquirer above. Finally, the greatest number of meetings take place between the highest $z$ acquirer and the lowest $z$ target, which is an acceptable match, giving that $(\mathrm{v})$ the highest rate of transaction occurs between low $z$ targets and high $z$ acquirers.

Proposition 3. The assumed symmetry of the merger technology along with the definition of the joint surplus in (12) immediately imply that (i) $\Sigma\left(z_{1}, z_{2}\right)=\Sigma\left(z_{2}, z_{1}\right)$ and that (ii) matching sets are symmetric around the $45^{\circ}$ line. Conjecture that $\lambda(z)=K \mu(z), K>1$, that is, for each firm, search intensity on the acquiring side of the market is some constant proportion of search intensity on the the target side. Then, $\int \lambda(z) d G(z)=K \int \mu(z) d G(z)$, that is, the aggregate search intensity of acquirers is the same proportion of the aggregate search intensity of targets. This implies $j_{a}<1$ 
and $j_{t}=1$. Expected surplus conditional on meeting a prospective buyer is

$$
\begin{aligned}
E\left[M_{t}(z)\right] & =(1-\beta) \int \max \left\{\Sigma\left(z_{a}, z\right), 0\right\} \Lambda\left(z_{a}\right) d G\left(z_{a}\right) \\
& =(1-\beta) \int \max \left\{\Sigma\left(z_{a}, z\right), 0\right\} \frac{\lambda\left(z_{a}\right)}{\int \lambda\left(z_{a}\right) d G\left(z_{a}\right)} d G\left(z_{a}\right) \\
& =(1-\beta) \int \max \left\{\Sigma\left(z, z_{t}\right), 0\right\} \frac{K \mu\left(z_{t}\right)}{K \int \mu\left(z_{t}\right) d G\left(z_{t}\right)} d G\left(z_{t}\right) \\
& =(1-\beta) \int \max \left\{\Sigma\left(z, z_{t}\right), 0\right\} \frac{\mu\left(z_{t}\right)}{\int \mu\left(z_{t}\right) d G\left(z_{t}\right)} d G\left(z_{t}\right) \\
& =(1-\beta) \int \max \left\{\Sigma\left(z, z_{t}\right), 0\right\} \Gamma\left(z_{t}\right) d G\left(z_{t}\right) \\
& =\frac{1-\beta}{\beta} E\left[M_{a}(z)\right]
\end{aligned}
$$

That is, the expected surplus conditional on meeting a prospective buyer is a constant multiple of the expected surplus conditional on meeting a prospective target, and simply depends on the ratio of bargaining powers. Note that in the third line, I have used the symmetry assumption on the technology, as well as the initial conjecture that search intensities are in constant proportion. From the first order conditions governing optimal search (19), we can see that if expected surplus is in constant proportion, than search intensities will as well, verifying our initial conjecture. Similar reasoning holds for the cases of $K<1$ and $K=1$.

From (10), the mass of meetings where $z_{1}$ is the acquirer and $z_{2}$ is the target is equal to

$$
\frac{\lambda\left(z_{1}\right) j_{a} \mu\left(z_{2}\right) d G\left(z_{2}\right)}{\int \mu(z) d G(z)} M d G\left(z_{1}\right)
$$

The mass of meetings of the opposite kind where the roles are reversed is

$$
\frac{\lambda\left(z_{2}\right) j_{a} \mu\left(z_{1}\right) d G\left(z_{1}\right)}{\int \mu(z) d G(z)} M d G\left(z_{2}\right)
$$

Substituting $\lambda(z)=K \mu(z)$ in both expressions, we obtain

$$
\frac{K \mu\left(z_{1}\right) j_{a} \mu\left(z_{2}\right) d G\left(z_{2}\right)}{\int \mu(z) d G(z)} M d G\left(z_{1}\right) \text { and } \frac{K \mu\left(z_{2}\right) j_{a} \mu\left(z_{1}\right) d G\left(z_{1}\right)}{\int \mu(z) d G(z)} \operatorname{MdG}\left(z_{2}\right)
$$

which are equivalent. Thus, each transaction is reflected in equal weight by its counterpoint transaction with the roles reversed. It is then immediate that (iii) the mean and median difference between acquirers and targets is zero. 


\section{Computational Algorithm}

In this Appendix, I describe in more detail the computational algorithm used for calibration of the model.

I discretize the productivity distribution over $z$ into 500 points from a $z$ of 1 , which corresponds to the normalization of $\hat{z}$ described above, up to a $z$ of 10,000 . Recalling from (6) that the ratio of the size of two firms is equal to the ratio of their $z^{\prime}$ s, I follow Restuccia and Rogerson (2008) in constructing a grid such that the largest operating firm will be 10,000 times the size of the smallest, and additionally in log-spacing the grid to ensure greater accuracy over the lower tail of the distribution, where most firms reside. I then construct the endogenous distribution $d G(z)$ over this grid such that $d G(z)$ takes on a Pareto with shape parameter $\xi$. Next, I guess a candidate value of $\Theta^{c}=\left\{\gamma, v, A, \beta, \eta, \mu^{c}, j_{a}, j_{t}\right\}$. With the candidate values of $A, \gamma$, and $\nu$, I can construct a "merger matrix" which represents the $z_{m}$ resulting from each combination of $z_{a}$ and $z_{t}$, where the two pre-merger firms are drawn from the entire set of $z^{\prime}$ s. That is, the merger matrix contains the effective productivity of the merged entity formed by the merger of all possible combinations of $z^{\prime}$ s.

Computation of the equilibrium begins by guessing the industry aggregate $D=R P^{\sigma-1}$, which through (6) determines variable profits from sales. From (26), it is straightforward to show that total revenue $R=P Y=\frac{1}{\rho} L$, that is, total revenue is pinned down by the elasticity of substitution in production of the final good and the size of the population. Using this, I can compute the aggregate price $P$. I perform value function iteration to find $V(z), \lambda(z), \mu(z), \mathrm{Y}_{t}(z), \mathrm{Y}_{a}(z)$. For a candidate $V(z)$, I use the merger matrix to compute the value of each potential transaction on the merger market and in particular, to find those generating positive surplus. I then use an iterative procedure to construct optimal search intensities, by which I guess a candidate vector $\mu(z)$, solve for $\lambda(z)$ and recompute $\mu(z)$. Recall that $\Theta^{c}$ contains a candidate $\mu^{c}=\int \mu(z) d G(z)$, from which, in conjunction with the values of $j_{a}$ and $j_{t}$, it is straightforward to compute aggregate search on the opposing side of the market $\int \lambda(z) d G(z)$. Given a feasible vector $\mu(z)$, a straightforward manipulation of the first order condition (19) along with the parameterization (27) gives an expression for $B$ that is independent of the individual values of $\lambda(z)$ :

$$
B=\left(\frac{1}{\int \lambda(z) d G(z)}\right)^{\eta-1}\left(\int\left\{E\left[M_{a}(z)\right]\right\}^{\frac{1}{\eta-1}} d G(z)\right)^{\eta-1}
$$

where $E\left[M_{a}(z)\right]$ is as defined in (17) and depends on objects that are known (for this candidate parameter vector). With this value of $B$, I can construct $\lambda(z)$. An analogous procedure gives $C$. Finally, I compute a new value of $\mu(z)$ as a function of $\lambda(z)$ and the inferred values of $B$ and $C$. I iterate on this process until $\mu(z)$ converges.

It is now straightforward to construct new values of $V(z)$ in accordance with (18). In doing so, I compute the fixed $\operatorname{cost} c_{f}$ that is consistent with this equilibrium by solving $V(\hat{z})=0$. Next, I use the firm search and matching decisions to construct the flows in (22) and in conjunction with 
the distribution $d G(z)$, I infer the entry distribution $d F(z)$. Here, I must make a normalization of the minimum possible draw of $z, z_{\min }$, which I set to 0.3 . Finally, I use $V(z)$ and $d F(z)$ to construct the free entry condition (15) and iterate on the candidate value of $D$ until the free entry condition is satisfied.

To simulate the economy, I draw 1 million firms from the stationary distribution $d G(z)$ and compute revenues, labor demand, and values functions. Standard arguments show that each acquirer has a probability of meeting a target in a single period equal to $1-e^{-\lambda(z)}$. Using these probabilities, I calculate the set of potential acquirers and match them to a set of potential targets who are drawn randomly according to their meeting probabilities $1-e^{-\mu(z)}$. Elimination of matches that generate negative surplus gives a simulated merger dataset with matched acquirers and targets analogous to the actual data described above. It is then straightforward to calculate the target moments and compute the value of the objective function in (29). I iterate on the guess of $\Theta^{c}$ until this function is minimized. 